\title{
Did Attitudes Interpret and Predict "Better" Choice Behaviour towards Innovative and Greener Automotive Technologies? A Hybrid Choice Modelling Approach
}

\author{
Stefano de Luca $(\mathbb{D})$ and Roberta Di Pace $\mathbb{D}$ \\ Department of Civil Engineering, University of Salerno Italy, Fisciano, Italy \\ Correspondence should be addressed to Stefano de Luca; sdeluca@unisa.it
}

Received 5 December 2019; Revised 29 June 2020; Accepted 3 July 2020; Published 1 August 2020

Academic Editor: Ludovic Leclercq

Copyright (c) 2020 Stefano de Luca and Roberta Di Pace. This is an open access article distributed under the Creative Commons Attribution License, which permits unrestricted use, distribution, and reproduction in any medium, provided the original work is properly cited.

\begin{abstract}
It is common opinion that traditional approaches used to interpret and model users' choice behaviour in innovative contexts may lead to neglecting numerous nonquantitative factors that may affect users' perceptions and behaviours. Indeed, psychological factors, such as attitudes, concerns, and perceptions may play a significant role which should be explicitly modelled. By contrast, collecting psychological factors could be a time and cost consuming activity, and furthermore, real-world applications must rely on theoretical paradigms which are able to easily predict choice/market fractions. The present paper aims to investigate the above-mentioned issues with respect to an innovative automotive technology based on the after-market hybridization of internal combustion engine vehicles. In particular, three main research questions are addressed: (i) whether and how users' characteristics and attitudes may affect users' behaviour with respect to new technological (automotive) scenarios (e.g., after-market hybridization kit); (ii) how to better "grasp" users' attitudes/concerns/perceptions and, in particular, which is the most effective surveying approach to observe users' attitudes; (iii) to what extent the probability of choosing a new automotive technology is sensitive to attitudes/concerns changes. The choice to install/not install the innovative technology was modelled through a hybrid choice model with latent variables (HCMs), starting from a stated preferences survey in which attitudes were investigated using different types of questioning approaches: direct questioning, indirect questioning, or both approaches. Finally, a comparison with a traditional binomial logit model and a sensitivity analysis was carried out with respect to the instrumental attributes and the attitudes. Obtained results indicate that attitudes are significant in interpreting and predicting users' behaviour towards the investigated technology and the HCM makes it possible to easily embed psychological factors into a random utility model/framework. Moreover, the explicit simulation of the attitudes allows for a better prediction of users' choice with respect to the Logit formulation and points out that users' behaviour may be significantly affected by acting on users' attitudes.
\end{abstract}

\section{Introduction and Motivations}

The diffusion and market penetration of new technologies is becoming a crucial factor for transport system analysts and decision-makers. Among the several new technologies aiming to render the transportation system more efficient and sustainable, Electric Vehicles (EV) or Hybrid Electric vehicles (HEV) represent one of the possible solutions, but although electric technologies are consolidated and reliable, two main issues continue to be challenging tasks: interpreting and modelling users' behaviour towards these new technologies and assessing the potential environmental impacts.
Within the cited context, it is common opinion that traditional approaches used to interpret and model users' choice behaviour may lead to neglecting the numerous nonquantitative factors that may affect users' perceptions and behaviours.

As a matter of fact, psychological factors, such as attitudes, concerns, and perceptions may play a significant role which should be explicitly modelled. On the other hand, collecting psychological factors could be a time and cost consuming activity and, furthermore, real-world applications must rely on theoretical paradigms able to easily predict choice/market fractions. 
Over the last two decades, users' propensity to choose alternative fuel vehicles (AFVs) has been widely investigated, and many recent analyses have pointed out the necessity to also take into account nonobservable variables such as the perceptions and the attitudes of the users (see [1]) along with directly observable/measurable attributes. Indeed, even though models usually adopted in demand modelling are suitable for the representation of the choice process, these cannot be applied to the representation of perceptions and attitudes [2].

Based on previous considerations several researchers have proposed the integration of latent variables within traditional econometric frameworks, such as the utilitarian theoretical paradigm. Therefore, Latent variables Hybrid Choice Models (HCMs) have been adopted in several cases, and in particular, they have been applied to capture the individual attributes, such as attitudes and habit influencing: the mode choice [3-10], the residential location choice $[11,12]$, the route choice decision making [13-15], and the vehicles choice (see Section 2).

The present paper, starting from some preliminary results proposed in de Luca and Di Pace [16]; aims to investigate the role of attitudinal factors in the choice of a new automotive technology, the HySolarKit, which aims to electrify/hybridize existing vehicles through an after-market kit which can be recharged by the grid, as well as by solar power [17-21].

The paper first proposes a literature review on the most significant contributions on users' intention to purchase electric/hybrid automotive technologies, with particular attention to the psychological factors and the possible modelling approaches.

It then addresses the following three main research questions (The main aim is not to investigate the potentialities of the HySolarkit, but to comprehend the role of attributes different from typical instrumental attributes):

(1) Whether and how users' characteristics and attitudes may affect users' behaviour with respect to new technological (automotive) scenarios (e.g., aftermarket hybridization kit), thus if users' choice should be investigated through more advanced and behaviourally complex models

(2) How to better "grasp" users' attitudes/concerns/ perceptions and, in particular, which is the most effective surveying approach to observe users' attitudes, through which type of questions (e.g., direct or indirect) and through which questions

(3) To what extent the probability of choosing a new automotive technology may be significantly affected by attitudes/concerns changes

The above-mentioned issues were addressed through the implementation of an "ad hoc" experiment and a model based analysis aimed to infer the role of psychological factors through the specification of latent variables within a Random Utility theory modelling framework.

To this aim, a Stated Preferences (SP) survey was carried out on a sample of potential consumers [22]. In particular, the survey aimed to collect the propensity to install the HySolarKit, but it was specifically designed to "grasp" five different attitudes/concerns through a direct questioning approach (attitudes towards the environment, design, fuel consumption, technology, and reliability of technology).

Different types of questions were tested: "directly related to the alternative" and "indirectly related to the alternative" questions (details in Section 4.2). Indeed, existing literature makes use of direct questioning, but usually uses alternative related questions only $[23,24]$, whilst there are fewer instances of resorting to a mix of alternative and nonalternative related questions. Experimental results were first analysed to investigate the robustness of the adopted hypotheses/questions; then they were used for calibrating hybrid choice models (HCMs) with latent variables, followed by a traditional binomial Logit model.

The estimation results made it possible to understand the effectiveness of the different surveying methods and the role of psychological factors in the choice behaviour and also allowed for investigating if and how the inclusion of attitudinal factors significantly increases choice model goodness-of-fit, thus leading to much more effective results than traditional Logit choice models. Finally, a sensitivity analysis was carried out for assessing the role of traditional instrumental attributes (e.g., monetary cost), as well as the impacts that the change of users' attitudes may have on the propensity to install the new technologies.

The paper is organised as follows. Section 2 introduces the state of the art on existing approaches and modelling solutions to the simulation of the propensity to choose new automotive technologies. Section 3 introduces the theoretical frameworks, whereas Section 4 describes the experimental framework introducing the case study, the data collection, and the preliminary analyses. Finally, Section 5 discusses the estimation results. The main conclusions are summarised in Section 6.

\section{Intention to Choose Electric or Hybrid Electric Automotive Technologies: Modelling Approaches and Determinants}

The interest in alternative fuel vehicles (AFV) relies on a wide range of literature whose main focus is that of Electric (EVs), Hybrid (HEVs), or Plug-In Electric vehicles (PHEVs).

As highlighted in studies of de Luca et al. [16] and Cartenì et al. [25], the choice phenomenon cannot be solely interpreted within a unique theoretical framework. As a matter of fact, eliciting the "preference" for AFVs is quite complicated due to several factors, such as the recent adoption of such technologies, the unavailability of sales data, the difficulty of estimating the ownership costs, and the impacts on driving habits.

Behavioural approaches on EVs choice mainly rely on two mainstreams theories: (i) psychological and sociological theories (Theory of Planned Behaviour-TPB; Value-BeliefNorm theory-VBN; habits, diffusion of innovation, diffusion theory) and (ii) Consumer Choice Theory (CCT). 
Psychological approaches made it possible to comprehend the complexity of the phenomenon, allowing for the understanding of the main determinants that may affect $\mathrm{E} /$ H/PHEVs consumer adoption [26-34].

The cited psychological approaches have proposed qualitative and quantitative results grounded on descriptive statistical analyses, making it possible to comprehend the main barriers and determinants that may affect E/H/PHEVs consumer adoption. The main results, applied to EVs, indicated the significance of hedonic and symbolic attributes, or emotions and feelings [30] (instrumental attributes refer to the functionality or utility that can be derived from functions performed by new technologies; hedonic attributes refer to the pleasure of using a new technology; symbolic attributes are related to a sense of self or social identity that is reflected by the possession of new technologies); factors expressing self-identity and/or lifestyle $[30,32,35,36]$; and pleasure or enjoyment gains and minimisations of negative effects when making journeys [37-39].

CCT can count on a wide range of models and applications investigating alternative fuel vehicle (AFV) market penetration and/or consumer behaviour determinants [40-46].

The most significant contributions on EVs are mainly grounded on Random Utility Theory, and starting from the year 2000, different modelling solutions have been successfully proposed: the Rank ordered model [47]; the Mixed (Hybrid) Multinomial Logit models [48-50]; the Multinomial Logit models or the Nested Logit models [51-55]; the multiple discrete-continuous model [56]; and the utility-based and a regret-based model of consumer preferences [57].

Proposed analyses, together with typical instrumental and easily quantifiable attributes (e.g. range, maintenance, driving costs, and ownership costs), point out that other attributes may play a significant role.

Indeed, the decision to install/purchase/adopt an E/PE/ PHEVs depends on several attributes of different types: instrumental, environmental, hedonic, and symbolic $[35,58-62]$.

E/H/PHEVs' are usually judged with respect to the instrumental and functional attributes: purchase price, running costs, reliability, performance, driving range and recharging time, performance, convenience, comfort, and aesthetics [16, 22, 35, 36, 40, 53, 63-68].

Recently, an increasing number of contributions have pointed out the role of noninstrumental attributes such as household socioeconomic characteristics $[48,50,69]$, social influence [70], consumer emotions and feelings [28, 30, 36, 39], proenvironmental behaviour [71, 72] and [73], consumer adoption of innovations $[74,75]$, governmental incentive [50], and hedonic and symbolic attributes [35, 58-61].

Among the wide variety of the existing contributions, significant efforts have been made to analyse the attitudes that potentially may affect the users' choice process of purchasing an E/H/PHEVs'.

Along with different approaches founded on psychological paradigms but which are not able to foresee the adoption of innovative technologies, Hybrid Choice models
(HCMs) with latent variables may allow for the role of perceptions and attitudes to emerge and, at the same time, estimate the probability of choosing/adopting the technology.

One of the first contributions was by Choo and Mokhtarian [76] who analysed the attitudes, lifestyles, personalities, and mobility which more generally may affect consumers' choice in identifying the vehicle type. In particular, seven groups of significant variables were identified: (i) the objective mobility, such as commute time, travelled distance, and frequency of trips; (ii) the subjective mobility focusing on how that amount of travel is perceived; (iii) how respondents enjoy travelling themselves; (iv) the attitudes in terms of travel, land use, and environment; (v) the personality; and (vi) the lifestyle.

A contrasting result was proposed by Kishi and Satoh [77] for the Tokyo and Sapporo residents, which, though well aware of environment concerns, were not inclined to purchase low-pollution cars.

Proenvironment propensity was derived by Potoglou and Kanaroglou [52] who observed how the propensity to adopt cleaner vehicles of Canadians' households was mainly affected by the reduction in the monetary costs and purchase tax reliefs along with the low emission rates.

Bolduc et al. [48], starting from a survey conducted by the Energy and Materials Research Group (Simon Fraser University, 2002 and 2003), identified two main latent variables which have a positive impact on the choice probability of the green technology alternatives: (i) the environmental concern related to transportation and its environmental impact, and (ii) the appreciation of new car features related to car purchase decisions.

A similar study, conducted by the same researchers [78], still observed that an environmentally conscious consumer would prefer a cleaner automobile technology associated with less environmental impact.

Jensen [79] carried out a survey based on direct questions, and, unlike other research studies, they included attributes regarding charging possibilities and battery lifetime in the experiment, and users were also provided with information on recharging types and environmental impacts. Furthermore, they observed that purchase price (the full price paid for the car considering everything), driving range (the maximum distance that could be covered with a full tank or a fully charged battery), top speed, fuel cost, battery life, and charging in city centres and train stations have a significant effect on users' choices.

In [80], Jensen et al. investigated the users' attitudes through 27 statements regarding new technologies, the environment, car interest, and EVs in general. They carried out a before and after analysis modelling the choice between conventional and electric cars and found that environmental concern had a positive effect on the preference for EVs, both before and after the test period.

In the same year, Glerum et al. [50] provided a methodology based on HCM to forecast the demand for electric cars. They considered an SP survey collected within a project between Renault Suisse S. A. and EPFL's Transportation Center (TraCe). In particular, respondents were provided with some statements based on alternative related questions 
in order to collect the importance of car design, the perception of leasing, the perception of an electric vehicle as an ecological solution, the attitude towards new technologies, and the reliability, security, and use of an electric vehicle. The results indicated that only two attitudes were significant: the proleasing attitude and a proconvenience attitude (spaciousness, comfort, and new propulsion).

Soto et al. [81] investigated four technological alternatives and identified four latent variables: the environmental concern, the support for transport policies, and the attitude towards technology and car. Unlike other authors, during the experiment, they provided users with statements based on direct and nonalternative related questions.

More recently, Kim et al. [23, 24] investigated the intention to purchase an electric car and observed that the attitudes playing a role regarded the environmental, the economic, the battery, the technological aspects, and the innovation value. To this aim, a questionnaire based on nonalternative related questions was carried out. Moreover, they also considered socioeconomic characteristics in the structural model and the price of EC, the cost electricity relative to gas, the cruising range of the car, the time to charge the battery, the maximum speed car, and the distance to charging station as alternative attributes in the logit model.

Similar results were obtained by Petsching et al. [34] who investigated the interest for hybrid vehicles through the paradigm of the "Theory of Innovation Adoption" and identified the significant role of the perception of innovation correlated to factors such as ecology, design, profitability, and ease of use.

Finally, Tsouros \& Polydoropoulou [82] investigated a choice context including four alternatives (i.e., a hybrid car, an electric car, a diesel car, or a standard car) through an SP experiment and observed environmental awareness as the only significant attitude. They considered the vehicles' characteristics (e.g., the engine size, the vehicle type, and the vehicle edition) and the individuals' socioeconomic characteristics for the structural equation and depicted the attitude through indicators (indicators of eco-friendliness) based on nonalternative related questions, which include perceptions regarding ecological habits such as recycling, active transportation, and how they perceive each fuel type. As in the studies of Bolduc et al. [48], Daly et al. [83], and Soto et al. [81], a comparison of the obtained results with the MNL model is provided confirming that HCM exhaustively outperforms MNL.

Although the comparative analysis among different contributions is not straightforward, since the surveys (which are not always discussed in depth) and the corresponding questionnaires are not comparable and the case studies are different with regard to EV technologies penetration, some conclusions may be drawn.

Indeed, it is interesting to highlight how the attitude towards the environment is present in the greatest number of studies. In general, almost all the existing analyses are founded on SP experiments and make use of alternative related $[48,50,79]$ or nonalternative related questions $[23,24,84]$ to "grasp" users' latent characteristics.

Latent variables are usually used for describing attitudes, but also concerns and/or perceptions and all the contributions, except for the proenvironmental attitude, investigate different sets of attitudes/perceptions/concerns.

With reference to the identification of modelling approach effectiveness, most of the contributions do not propose any comparison, whilst Bolduc et al. [48], Soto et al. [81], and Ioannis et al. [84] highlighted that hybrid choice models normally outperform traditional random utility models.

In the following table, a synoptic framework of the state of the art is proposed. The main contributions discussed above have been classified with respect to the adopted theoretical paradigm, the investigated case study, and the used attributes (instrumental and noninstrumental) (Table 1).

\section{Theoretical Framework}

The modelling approach adopted in this paper was based on the Hybrid Choice Model focusing on the incorporation of latent variables into discrete choice models.

Seminal studies aiming to overstep the boundary of standard discrete choice models were conducted by Ortúzar and Hutt [85] and McFadden [86] in which during the 80s, they investigated the possibility of including subjective variables in a discrete choice modelling [1, 8, 9, 87-97].

Traditionally hybrid choice models are composed of the latent variable (LV) model and the choice model. In general, the representation of parameters related to the psychological model may be pursued through different approaches: (i) by including the indicators directly in the utility function [98-100]; (ii) by considering a sequential method in which, at the first stage, latent variables are represented through the Explanatory Factorial Analysis (EFA); then these are directly included in the utility function [101]; and (iii) by the MIMIC model (Multiple Indicator Multiple Cause; [102] in which the relationship between attitudes (latent variables) and sociodemographic characteristics is formalised by the structural equation, and the relationship between attitudes and perception indicators is formalised by measurement equation; then latent variables are directly incorporated in discrete choice model.

In this paper, the MIMIC approach has been adopted; then the utility in the (hybrid) choice model based on the assumption that each individual $n(n=1, \ldots, N)$ faced with a set of alternatives $i(i=1, \ldots, \mathbf{I})$, may be expressed as a function of a vector of observed attributes $\mathbf{X}_{n i}$ (representing the level of service and the users' attributes), a vector of latent variables, $\mathbf{L V}_{n i}(K \times 1$, if $K$ statements are considered for each LV), and the error term $\varepsilon_{i n}$, independently and identically distributed; thus for each alternative, the perceived utility may be expressed as

$$
U_{n i}=\boldsymbol{\beta} x \cdot \mathbf{X}_{n i}+\boldsymbol{\beta}_{\mathbf{L V}} \cdot \mathbf{L} \mathbf{V}_{n i}+\varepsilon_{n i},
$$

and the choice principle of the alternative, considering the chosen $y_{i}$ alternative, is based on utility maximisation criterion.

Regarding the $\mathrm{LV}$, let be $p$ the generic latent variable to be measured by psychometric indicators $(p=1, \ldots, P)$ and $k$ be the generic psychometric indicator $(k=1, \ldots, K)$, the latent variable model consists in two equations for each latent variable (LV); in particular for each individual $n$, the structural equation may be expressed as follows: 
TABLE 1: Synoptic framework of the state of the art.

\begin{tabular}{|c|c|c|c|c|c|c|c|c|}
\hline \multirow[b]{2}{*}{ Reference } & \multicolumn{4}{|c|}{ Paradigms } & \multicolumn{3}{|c|}{ Investigated case study } & \multirow[b]{2}{*}{ Attribute(s) } \\
\hline & PST & CCT & RUT & Others & $\begin{array}{c}\text { AFV } \\
\text { purchase/ } \\
\text { intention }\end{array}$ & $\begin{array}{c}\text { Environmental } \\
\text { behaviour }\end{array}$ & $\begin{array}{l}\text { Adoption of } \\
\text { innovations }\end{array}$ & \\
\hline $\begin{array}{l}\text { Beggs et al., [40]; } \\
\text { Bunch et al., [63]; } \\
\text { Chéron and Zins, [64]; } \\
\text { Ong and Hsselhoff, [65]; } \\
\text { Musti and Kockelman, [66]; } \\
\text { Graham-Rowe et al., [36]; } \\
\text { He et al., [67]; } \\
\text { de Luca et al., [16]; de Luca and } \\
\text { di Pace, [22] }\end{array}$ & & . & . & . & $\begin{array}{l}\cdot \\
\cdot \\
\cdot \\
\cdot \\
\cdot \\
\cdot \\
\cdot \\
\cdot\end{array}$ & & & $\begin{array}{l}\text { Instrumental and functional } \\
\text { attributes: purchase price, } \\
\text { running costs, reliability, } \\
\text { performance, driving range } \\
\text { and recharging time, } \\
\text { performance, convenience, } \\
\text { comfort, and aesthetics }\end{array}$ \\
\hline $\begin{array}{l}\text { Plotz et al., [69]; } \\
\text { Bolduc and Daziano, [48]; } \\
\text { Glerum et al., [50] } \\
\text { Choo and Mokhtarian [76] } \\
\text { Potoglou and Kanaroglou [52] }\end{array}$ & & . & $\begin{array}{l}. \\
. \\
.\end{array}$ & & $\begin{array}{l}\cdot \\
. \\
. \\
.\end{array}$ & & & $\begin{array}{c}\text { + not-instrumental } \\
\text { attributes: Household } \\
\text { socioeconomic } \\
\text { characteristics, attitudes, } \\
\text { personality, and lifestyle. }\end{array}$ \\
\hline $\begin{array}{l}\text { Axsen and Kurani, [70] } \\
\text { Moons and de Pelsmacker, } \\
\text { [28]; } \\
\text { Schuitema et al., [30]; } \\
\text { Graham-Rowe et al., [36]; } \\
\text { Steg, [39] } \\
\text { Bamberg and Möser, [71] } \\
\text { Onwezen et al., [72]; } \\
\text { Steg and Vlek, [73] } \\
\text { Shih and Schau, [74] } \\
\text { Watson and Spence, [75] } \\
\text { Petsching et al. [34] } \\
\text { Kishi and Satoh [77]; Bolduc } \\
\text { and Daziano, [48] Daziano and } \\
\text { Bolduc, [78]; Jensen, [79]; } \\
\text { Glerum et al, [50]; Soto et al. } \\
\text { [81]; Kim et al. [23, 24]; Ioannis } \\
\text { et al., [84]; Tsouros \& } \\
\text { Polydoropoulou [82] }\end{array}$ & $\begin{array}{l}\cdot \\
\cdot \\
. \\
\cdot \\
\cdot \\
\cdot \\
\cdot \\
\cdot \\
\cdot \\
\cdot\end{array}$ & . & . & & $\begin{array}{l}. \\
.\end{array}$ & $\begin{array}{l}. \\
. \\
.\end{array}$ & . & $\begin{array}{l}\text { + not-instrumental } \\
\text { attributes: norms, cognitive, } \\
\text { emotions, feelings, motives, } \\
\text { social factors/influence, } \\
\text { attitudes, anticipated regret }\end{array}$ \\
\hline
\end{tabular}

$$
\mathbf{L V}_{n i}=\gamma+\boldsymbol{\beta} \cdot \mathbf{X}_{n i}+\omega_{n i}
$$

where $\gamma$ is the intersect, $\mathbf{X}_{\mathrm{ni}}$ is the vector of the users' characteristics, $\boldsymbol{\beta}$ is the vector of the coefficients associated with the users' characteristics (to be estimated), and $\omega_{n}$ be the error term which, usually, is distributed with zero mean and $\sigma_{\omega}$ standard deviation.

Furthermore, for each individual $n, K$ statements are used; thus, $\mathbf{I}_{n i}$ is a vector of perceptions indicators $(K \times 1)$ that are associated to the latent variable with the measurement equation given as follows:

$$
\mathbf{I}_{n i}=\alpha+\boldsymbol{\lambda} \cdot \mathbf{L V}_{n i}+v_{n i}
$$

where $\alpha$ is the intersect, $\lambda$ is the vector of coefficient associated with the latent variable (to be estimated), and $v_{n i}$ is the error terms usually assumed normally distributed with zero mean and $\sigma_{v}$ standard deviation.

Regarding the psychometric indicators, they may be represented in two different ways through continuous and discrete indicators, depending on the adopted coding approach. They are usually coded through the Likert scale [103] and the structural equation modelling may be based on the ordered logit model; the measurement is represented through a discrete variable and the thresholds are the parameters to be estimated [83]. A diagram of the model's specification is shown in Figure 1.

In terms of the estimation procedure, as previously outlined, two approaches may be distinguished: the sequential [3, 104, 105] and the simultaneous approaches [93].

The sequential approach solves the MIMIC model separately from the choice model; thus two stages must be considered: one for estimating latent variables using the perceptions indicators and the other one for estimating the parameters in the choice model related to the latent variables and to the typical variables. However, this approach was demonstrated as not being efficient (it cannot guarantee consistent and unbiased estimators) [43, 91, 106]. The simultaneous approach is based on a joint estimation procedure.

In this paper, the applied estimation procedure was based on the simultaneous approach. In general, latent variables are not directly observable, indicators are introduced, and any inference must be based on the joint distribution whose density can be rewritten as 


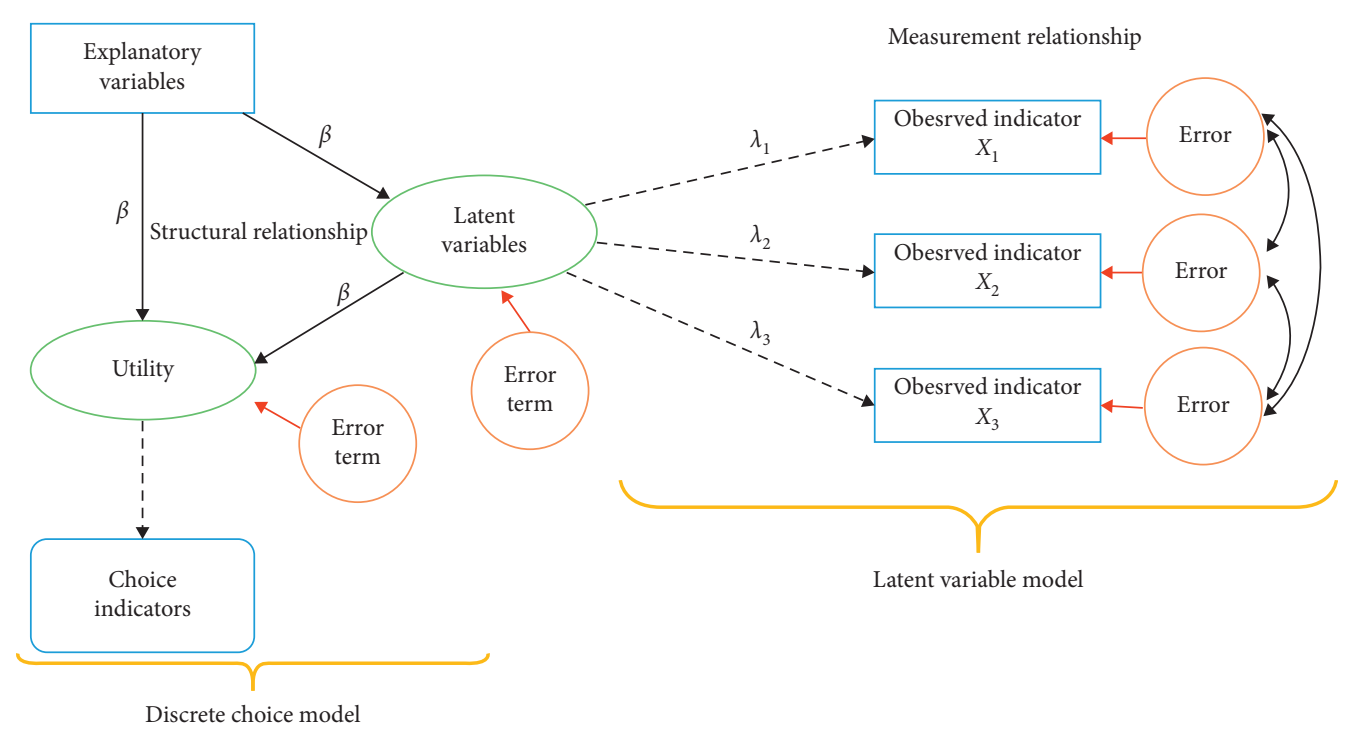

Figure 1: Diagram of a hybrid choice model (HCM).

$$
g\left(\mathbf{I}_{n i}\right)=\int R_{\mathrm{LV}_{n i}}\left(\frac{\mathbf{I}_{n i}}{\mathbf{L} \mathbf{V}_{n}}, \boldsymbol{\lambda}\right) \mathbf{h}_{\mathrm{LV}_{n i}}\left(\frac{\mathbf{L} \mathbf{V}_{n i}}{\mathbf{X}_{n i}}, \boldsymbol{\beta}\right) \mathrm{d} \mathbf{L} \mathbf{V}_{n i},
$$

where $R_{\mathrm{LV}_{n i}}$ is the range space of the vector of the latent variables.

The joint probability of observing the choice $y_{n i}$ may be expressed as

$$
\begin{aligned}
\mathbf{P}\left(y_{n i}, \frac{\mathbf{I}_{n i}}{\mathbf{X}_{n i}}, \boldsymbol{\beta}_{x}, \boldsymbol{\beta}_{\mathrm{LV}}\right)= & \int \mathbf{R}_{\mathrm{LV}_{n i}} \mathbf{P}\left(\frac{y_{n i}}{\mathbf{X}_{n i}}, \boldsymbol{\beta}_{x}, \boldsymbol{\beta}_{\mathrm{LV}}\right) \\
& \cdot f_{I_{n i}}\left(\frac{\mathbf{I}_{n i}}{\mathbf{L} \mathbf{V}_{n}}, \boldsymbol{\lambda}\right) \mathbf{h}_{\mathrm{LV}_{n i}}\left(\frac{\mathbf{L V}}{\mathbf{X}_{n i}}, \boldsymbol{\beta}\right) \mathrm{d} \mathbf{L} \mathbf{V}_{n i},
\end{aligned}
$$

where $f(\cdot)$ is the probability density function of the perception indicators and $h(\cdot)$ is the probability density function of the latent variables.

Parameters estimation is carried out by maximising the joint likelihood of observed sequence of choices and the observed answers to the attitudinal questions:

$$
\begin{aligned}
\mathbf{L} & =\Pi_{i} \mathbf{P}\left(y_{n i}, \frac{\mathbf{I}_{n i}}{\mathbf{X}_{n i}}, \boldsymbol{\beta}_{x}, \boldsymbol{\beta}_{\mathrm{LV}}\right) \\
& =\int R_{\mathrm{LV}_{n i}} \boldsymbol{\Pi}_{i} \mathbf{P}\left(\frac{y_{n i}}{\mathbf{X}_{n i}}, \boldsymbol{\beta}_{x}, \boldsymbol{\beta}_{\mathrm{LV}}\right) f_{I_{n i}}\left(\frac{\mathbf{I}_{n i}}{\mathbf{L V}_{n}}, \boldsymbol{\lambda}\right) \mathbf{h}_{\mathrm{LV}_{n i}}\left(\frac{\mathbf{L} \mathbf{V}_{n i}}{\mathbf{X}_{n i}}, \boldsymbol{\beta}\right) \mathrm{d} \mathbf{L} \mathbf{V}_{n i},
\end{aligned}
$$

the estimation of this class of models requires multidimensional integrals with dimensionality given by the number of latent variables.

Finally, particular attention was paid to the implications related to the evaluation of attitudinal and perceptual variables [107, 108]. Indeed, any change in the perception's indicators may affect the LVs' meaning to the extent that the whole model must be reestimated $[3,48]$. As stated in Vij \& Walker [109], two main approaches may be adopted in order to observe the choice outcomes: the former formulating the choice probabilities as a function of the observable variables, and the latter formulating the choice probabilities as a function of both the observable variables and the measurement indicators.

In this paper, the second approach was adopted, and the distribution of the latent variables was assumed given by the measurement equations.

The model parameters were estimated through PythonBiogeme [110] in which the Maximum Simulated Likelihood is implemented [92, 111].

\section{Experimental Framework}

4.1. Observing and Measuring the Attitudes. One of the main issues related to the specification and estimation of an HCM relies on how to observe and quantify users' attitudes [112, 113], perceptions [114], or concerns.

Attitudes refer to the users' characteristics and their approach in real life and society and may be not related to the alternatives (nonalternative related attitudes) or related to the alternatives (alternative related attitudes).

Perceptions are, usually, interpreted as "alternative related" and refer to the users' interpretation and reaction to a stimulus [113]. However, concerns may be related to a specific problem/issue, and they may depend on the (choice) context (for example, the concern towards the environment may depend on the specific problem/activity carried out).

Since attitudes/perceptions/concerns are entities constructed to represent underlying response behaviour, they cannot be measured directly, but they could only be inferred studying behaviour which, in turn, might be reasonably assumed to indicate the attitudes themselves.

The behaviour may be one that occurs in a natural setting or in a simulated situation. In general, different approaches to measure attitudes may be pursued:

(i) Direct Observations: observing the ongoing behaviour of people in the natural setting or directly asking 
the respondents to state their feelings with regard to the issue under study. Direct observation of behaviour is not practicable if we want to have data on a large number of individuals. Moreover, observation of behaviour, even when the behaviour is the outcome of the attitude being studied, may tell us the direction of the underlying attitude (i.e., whether it is positive or negative), but it cannot as easily indicate the magnitude or strength of the attitude.

(ii) Direct questioning: asking as to what their feelings are. Direct questioning has been applied for studying attitudes, but it mainly serves for limited purpose of classifying respondents as favourable, unfavourable, and indifferent with regard to a psychological object. Moreover, individuals may possess certain attitudes and behave accordingly, but may not be aware of them. Thus, direct questioning or any other selfreport technique will be of little avail if the respondent has no access to his own attitudinal orientations, buried in the realms of the unconscious.

Within direct questioning, two further questioning approaches may be pursued:

(i) Through direct questions on the investigated attitude (e.g., how much is the environment important)

(ii) Through indirect questions (e.g., my home bulbs are energy efficient)

In general, direct questioning is the most pursued solution, since it makes it possible to control the investigated context (defining the scale of measurement), and it requires smaller times and costs.

In this interpretative context, attitudes can be "grasped" through direct or indirect questioning, but indirect questioning seems the "most correct" approach, whereas perceptions can be "grasped" through direct questioning only, and concerns can be "grasped" through direct questioning only.

In this paper, a direct questioning survey was designed and two different types of questions were submitted to the respondents: "directly related" (in the following direct questions-D) and "indirectly related" questions (in the following indirect questions-I).

In particular, the paper investigates the concerns and attitudes/perceptions/concerns towards the environment, the vehicle design, the fuel consumption, the technology, and the reliability of technology.

Direct questions aimed to investigate the users' concerns towards fuel consumption, vehicle design, environment, technology, and reliability of technology. Indirect questions aimed to investigate the users' attitudes towards fuel consumption, vehicle design, and environment.

An overview of the questions submitted to the respondents will be displayed in the following section.

4.2. Case Study: Survey, Attributes, and Preliminary Analyses. The analyses and model specifications were carried out within a research project supported by the University of
Salerno and regarding the city of Salerno (Salerno is the capital city of Salerno province (region of Campania, southern Italy), situated $55 \mathrm{~km}$ southeast of Naples. It has a population of approximately 130,000, 54,500 households, an area of about $60 \mathrm{~km}^{2}$, a residential density of 2,240 inhabitants per $\mathrm{km}^{2}$, and an average of 1.50 cars per household. Finally, four transport modes are usually available: car as a driver, walking, bus, and motorbike).

The questionnaire was built from an early survey [16] and inspired by the existing literature discussed in Section 2.

The potential attributes worthy of interest were first grouped into five subcategories: (i) socioeconomic attributes, (ii) trip purpose type, (iii) owned car characteristics engine, (iv) price compared to user's conventional car, and (v) psychological factors.

The survey consisted of a sample made up of 700 (the size was defined coherently with the indications proposed by Louviere et al. (2000)) and involved only respondents owning at least one car and declaring that he/she had the authority/power to make decisions regarding household car ownership (mainly householders). The questionnaire consisted of three parts.

The first part aimed to gather information on family characteristics (geographical, travel characteristics, socioeconomic, etc.), on respondents' concerns that usually affect the decision to buy a specific vehicle (e.g., fuel consumption, environmental impact, and vehicle design) and about the household cars (fuel supply, brand, and vehicles age).

Moreover, a first set of direct questions $(D)$ were submitted to the respondents (Table 2). As introduced in the previous section, the questions are directly related to environment, vehicle design, fuel consumption, technology, and reliability of technology.

In this case, each respondent was asked to rate, in the Likert scale (1: null; 2: mild; 3: moderate; 4: severe), how much each considered statement was important in the choice of a car.

In the second part, indirect questions about the users' attitudes were submitted to respondents (Table 3). They regarded psychological factors related to fuel consumption $\left(I_{\text {cons }}\right)$, vehicle design $\left(I_{\text {design }}\right)$, and environment $\left(I_{\text {env }}\right)$. Indirect questions were measured through a five preferences rating scale (1: totally disagree; 2 : disagree; 3 : indifference; 4 : agree; 5: totally agree).

The third part investigated the propensity to install the HySolarKit.

First of all, the respondents were introduced to the technology and its main characteristics (see appendix for some technical details): how it works, how it is installed, the different performances (e.g. acceleration, speed), and the environmental and fuel consumption benefits which can be achieved.

To this aim, each respondent was presented with a more accurate estimate of the benefits obtainable in terms of fuel consumption (based on the type of trip, on the number of kilometres travelled, and on the type of vehicle owned). In particular, the weekly $\Delta$ cost was calculated, and the users were asked to state the systematic and nonsystematic trip 
TABLE 2: Overview of direct questions submitted to the respondents.

\begin{tabular}{lc}
\hline Direct questions $(D)$ & \\
\hline$D_{\text {cons }}$ & One of the most important things in a car is the fuel consumption rate \\
$D_{\text {design }}$ & The car design is one of the most important factors in purchasing a car \\
$D_{\text {env }}$ & I normally behave or act to reduce the environmental impact of my actions \\
$D_{\text {rel }}$ & I prefer driving traditional fuelled vehicles since they guarantee a higher reliability \\
$D_{\text {technology }}$ & I am sensitive to all the technological features offered by a car \\
\hline
\end{tabular}

TABLE 3: Overview of indirect questions submitted to the respondents.

\begin{tabular}{|c|c|}
\hline \multicolumn{2}{|c|}{ Indirect questions $(I)$} \\
\hline$I_{\text {cons }} 1$ & The consumption and the energy class significantly influence my choice in purchasing an appliance \\
\hline$I_{\text {cons }} 2$ & I am usually attentive to the special offers of electric operators \\
\hline$I_{\text {cons }} 3$ & My home bulbs are energy efficient \\
\hline$I_{\text {cons }} 4$ & I usually evaluate the car efficiency concerning the car cost mileage \\
\hline$I_{\text {cons }} 5$ & I normally compare the fuel prices among different stations \\
\hline$I_{\text {cons }} 6$ & $\begin{array}{c}\text { When driving I am not willing to behave in a way that reduces the environmental impact (my driving behaviour is normally } \\
\text { aggressive) }\end{array}$ \\
\hline$I_{\text {design }} 1$ & When parking I am usually careful to avoid having my car damaged \\
\hline$I_{\text {design }} 2$ & I often read journals of design \\
\hline$I_{\text {design }} 3$ & When furnishing I am willing to buy pieces with modern design features and original details \\
\hline$I_{\text {design }} 4$ & I am willing to go to the body shop mechanic not only for major damages \\
\hline$I_{\text {design }} 5$ & I am willing to install not standard equipment (such as antitheft block shaft) in my own car \\
\hline$I_{\text {env }} 1$ & I often control the exhaust/emission system of my car \\
\hline$I_{\text {env }} 2$ & I consciously do separate waste collection (recycling) \\
\hline$I_{\text {env }} 3$ & I really enjoy spending my free time in parks, green areas to breathe clean area \\
\hline$I_{\text {env }} 4$ & How much do you agree with the following sentence: We must act and make decisions to reduce emissions of greenhouse gases \\
\hline$I_{\text {env }} 5$ & How much do you agree with the following sentence: The government should invest in low energy impact \\
\hline$I_{\text {env }} 6$ & I am not willing to use the car during the weekend to protect the environment and then reduce air pollution \\
\hline
\end{tabular}

characteristics. Starting from the stated characteristics, each respondent was faced with two different scenarios with different installation costs (ranging from 500 to 4,000 euros). The cost scenarios submitted to each respondent were independent of one another.

All the tested attributes are summarised in Table 4, whereas Tables 5 and 6 show the descriptive and statistical analyses carried out on the preferences collected through direct/indirect questions.

In Table 5, together with the mean values, the standard deviations, and Cronbach's alpha test results are proposed.

Means and standard deviations make it possible to understand the weight given by the respondents to each question, whereas Cronbach's alpha measures how the questions associated to each attitude are closely related to each other as a group (internal consistency).

Obtained results made it possible to identify the questions with higher dispersion with respect to the corresponding mean values; Cronbach's alpha tests confirmed the reliability of the chosen questions, but also pointed out the advisability of an exploratory Principle Factor Analysis (PCA) on all the indicators.

The analysis made it possible to identify the correlation between the statements, allowed for the identification of the latent variables (factors) and, thus, the main statements explaining them. Overall, three latent variables were revealed as statistically significant and, for each one of them, the representative statements were identified (Table 5). In particular, three factors, corresponding to three different latent variables, were clearly identified: (i) Factor 1 representing the attitudes towards fuel consumption

(ii) Factor 2 representing the attitude towards the vehicle design

(iii) Factor 3 representing the attitude towards the environment

Observing the loading factors reported in Table 4, it is also possible to derive the role and significance of the attitudinal statements for each factor: in factor 1 ("fuel consumption"), the significant statements were $Q_{\text {cons }}, I_{\text {cons }} 1,2,3$ (see Tables 2 and 3 for a detailed description of statements); in factor 2 ("vehicle design") were $I_{\text {design }} 1,3,4$ (see Table 3 for a detailed description of statements); in factor 3 ("environment") were $Q_{\text {env }}, I_{\text {env }} 2,3,4,6$ (see Tables 2 and 3 for a detailed description of statements).

Such results support an interesting interpretation of the phenomena, but also represent an important/fundamental input for the specification of the Hybrid choice model which will be proposed in the following section.

\section{Results and Discussion}

With regard to the experimental framework previously introduced, this section presents the main results obtained from the specification and calibration of different Hybrid Choice Model (HCM) structures with latent variables. Estimation results are organised into two sections.

The first section introduces the estimation results for the HCM and aims to propose a detailed analysis on the 
TABLE 4: Collected and investigated attributes.

\begin{tabular}{|c|c|c|c|c|c|}
\hline Attribute & Meaning & Type & SI & Min & Max \\
\hline Age & Age of the respondent & Continuous & Years & 24 & 70 \\
\hline Master's degree & Equal to 1 for users achieved this educational attainment & Binary & & 0 & 1 \\
\hline ZonRes & Equal to 0 for users living to the historical centre, 1 if in the outskirts & Binary & & 0 & 1 \\
\hline Diesel & Power supply of the owned car & Binary & & 0 & 1 \\
\hline CarAge & Age of the owned car on which the respondent would install the kit & Continuous & Years & 1 & 10 \\
\hline By car-shopping & Mode choice car and trip purpose shopping & Continuous & - & 0 & 0.93 \\
\hline By car-personal services & Mode choice car and trip purpose personal services & Continuous & - & 0 & 0.93 \\
\hline $\begin{array}{l}\text { Interested in electric } \\
\text { vehicle purchasing }\end{array}$ & $\begin{array}{c}\text { Equal to } 1 \text { for users which declared to be interested in electric vehicle } \\
\text { purchasing }\end{array}$ & Binary & - & 0 & 1 \\
\hline
\end{tabular}

(i) Design issues concern

(ii) Environment concern

(iii) Reliability concern

(iv) Technology concern

Conc_Consump

Conc_Design

Conc_Environ

Conc_Reliab

(v) Fuel consumption concern

Conc_Tech

Each respondent was asked to rate how the fuel consumption/vehicle

Binary attribute for

each scale

design/environment/technology/reliability of technology is

important in the decision of which car to purchase. The rating scale

and the value associated to each rate was: null importance (1), mild

(2), moderate (3), and severe (4).

Latent variable representing the attitude towards the fuel

Att_Consump consumption; the rating scale and the value associated to each rate

was: 1: Totally disagree; 2: Disagree; 3: Indifference; 4: Agree; 5: and

Continuous

Totally agree

Latent variable representing the attitude towards the vehicle design;

Att_Design $\begin{gathered}\text { the rating scale and the value associated to each rate was: } 1: \text { Totally Continuous } \\ \text { disagree; 2: Disagree; 3: Indifference; 4: Agree; 5: Totally agree }\end{gathered}$
Latent variable representing the attitude towards the environment;

Att_Design
$\begin{gathered}\text { the rating scale and the value associated to each rate was: } 1 \text { : Totally } \\ \text { disagree; } 2: \text { Disagree; 3: Indifference; 4: Agree; 5: Totally agree }\end{gathered}$
Latent variable representing the attitude towards the environment

Att_Environ the rating scale and the value associated to each rate was: 1: Totally

disagree; 2: Disagree; 3: Indifference; 4: Agree; and 5: Totally agree

$\Delta_{\text {cost }}=\mathrm{WC}_{\text {withoutK }}-\mathrm{Wc}_{\text {withK }} \quad$ Continuous $\quad € \quad-4.4 \quad 17.2$

The weekly cost considering two scenarios, with and without the kit, was computed in order to define the users' financial gain. Therefore, each respondent was preliminarily informed on the upfront cost, and successively he/

$\Delta_{\text {cost }}$ she was also informed on the weekly cost (combining the fuel consumption, the charging cost and the installation cost).

Obviously the cost estimation is based on the weekly kilometres travelled by each respondent.

TABLE 5: Summary of the mean values and the standard deviations of the collected preferences and Cronbach's alpha test.

\begin{tabular}{lcc}
\hline & Mean & \\
\hline Fuel consumption & & s.d. \\
$Q_{\text {cons. }}$ & 3.76 & 0.97 \\
$I_{\text {cons }} 1$ & 3.97 & 1.01 \\
$I_{\text {cons }} 2$ & 4.27 & 02 \\
$I_{\text {cons } 3}$ & 3.28 & 0.51 \\
$I_{\text {cons }} 4$ & 2.18 & 3.15 \\
$I_{\text {cons }} 5$ & 1.88 & 0.94 \\
$I_{\text {cons }} 6$ & 2.35 & 1.22 \\
& Cronbach's alpha $=0.658$ & \\
\hline Design & & \\
$Q_{\text {design }}$ & 3.21 & 0.92 \\
$I_{\text {design }} 1$ & 2.85 & 0.65 \\
$I_{\text {design }} 2$ & 1.76 & 0.79 \\
$I_{\text {design }} 3$ & 3.11 & 0.96 \\
$I_{\text {design }} 4$ & 4.08 & 0.94 \\
$I_{\text {design }} 5$ & 2.97 & 0.5 \\
- & - & 0.92 \\
& Cronbach's alpha $=0.527$ \\
\hline
\end{tabular}


TABLE 5: Continued.

\begin{tabular}{lcr}
\hline & Mean & s.d. \\
\hline Environment & & 0.91 \\
$Q_{\text {env. }}$ & 2.54 & 1.02 \\
$I_{\text {env }} 1$ & 2.11 & 0.59 \\
$I_{\text {env }} 2$ & 3.71 & 0.91 \\
$I_{\text {env }} 3$ & 3.21 & 0.76 \\
$I_{\text {env }} 4$ & 2.98 & 0.73 \\
$I_{\text {env }} 5$ & 1.97 & 0.87 \\
$I_{\text {env }} 6$ & 3.87 & \\
& Cronbach's alpha $=0.721$ & \\
\hline
\end{tabular}

Table 6: Principal component analysis.

\begin{tabular}{lcc}
\hline Factor & Indic & Loading \\
\hline & $\mathrm{Q}_{\text {cons }}$ & 0.628 \\
Factor 1 fuel consumption & $I_{\text {cons }} 1$ & 0.357 \\
& $I_{\text {cons }} 2$ & 0.567 \\
& $I_{\text {cons }} 3$ & 0.488 \\
\hline & $\mathrm{Q}_{\text {design }}$ & 0.328 \\
Factor 2 vehicle design & $I_{\text {design }} 1$ & 0.721 \\
& $I_{\text {design }} 3$ & 0.548 \\
& $I_{\text {design }} 4$ & 0.432 \\
\hline & $\mathrm{Q}_{\text {env }}$ & 0.567 \\
Factor 3 environment & $I_{\text {env }} 2$ & 0.355 \\
& $I_{\text {env }} 3$ & 0.618 \\
& $I_{\text {env }} 4$ & 0.712 \\
\hline
\end{tabular}

Significant statements are with values greater than 0.35 .

estimation results, on the Latent Variables specification, and on the resultant behavioural interpretation. The results also made it possible to identify the most effective type of questions able to "grasp" users' attitudes.

The second section investigates the differences between the HCM and a traditional Binomial logit model (BLM) in which typical sociodemographic characteristics and instrumental attributes were used. The comparison was carried out in terms of statistically significant attributes, ability to interpret the choice phenomenon, goodness-of-fit, and sensitivity to the monetary cost and to the attitudes.

\subsection{Hybrid Choice Model with Latent Variables Estimation} Results. The HCM was specified with utility functions which are linear in the attributes, considering the attributes introduced in Section 4 and embedding the LVs within the systematic utility functions. To this aim, both the structural and the measurement equations were specified and jointly calibrated on the preferences stated by respondents with reference to the questions introduced in Section 4.2.

Overall, the estimation results pointed out that the following groups of attributes were statistically significant, with signs of the parameters consistent with the expectations (Table 7):
(a) The respondents' sociodemographic characteristics
(b) The activity-related attributes
(c) The level of service attributes

(d) The attitudinal attributes

(e) The vehicle characteristics

It may be preliminarily observed that the following users' specific attributes were statistically significant: age, educational level, and the characteristics of the family's vehicle fleet. Moreover, the zone of residence, the car age, and having a diesel vehicle explicated users' behaviour.

In terms of activity-related attributes, significant attributes were travelling by car if the trip purpose is shopping and/or personal services.

Analysing the systematic utility functions, it is interesting to note how being older increases the not-install choice, thus confirming that younger people are more interested in technological innovation; regarding the educational level, people with a master's degree show a greater likelihood to install the kit.

Contrasting results may be observed for users living in different zones of residence. Indeed, people residing in the city centre show a smaller propensity to install the kit, due to reduced trip distance usually travelled and smaller interest in cost savings. By contrast, people living in the outskirts may benefit from a greater travel cost saving, due to the greater travel distances.

As regards vehicle fleet characteristics, the car age increases the choice to install the kit, whereas owning a diesel car negatively affects the propensity to install the kit. Indeed, in the former case, people may decide, due to the actual value of the vehicle, to consider the kit as an opportunity, still 
TABLE 7: Estimation results of HCM.

\begin{tabular}{|c|c|c|}
\hline \multirow{2}{*}{ Attribute } & \multicolumn{2}{|c|}{$\mathrm{HCM}$} \\
\hline & Install & Not-install \\
\hline Age & $+0.160(+1.87)$ & - \\
\hline Master's degree & $+0.156(+2.16)$ & - \\
\hline ZonRes & $+0.0761(+1.98)$ & - \\
\hline Diesel & - & $+0.479(+3.52)$ \\
\hline CarAge & $+0.0272(+1.55)$ & - \\
\hline By car-shopping & $+0.669(+1.490)$ & - \\
\hline By car-personal services & $+0.192(+2.53)$ & - \\
\hline$\Delta_{\text {cost }}$ & - & $+0.0638(+8.16)$ \\
\hline $\mathrm{LV}_{\text {Consumption }}$ & $+0.548(+2.55)$ & - \\
\hline $\mathrm{LV}_{\text {Design }}$ & - & $+0.0682(+2.46)$ \\
\hline $\mathrm{LV}_{\text {Environment }}$ & $+0.104(+1.98)$ & - \\
\hline$\delta^{1}$ & $+1.46(+38.90)$ & - \\
\hline$\delta^{2}$ & $+1.34(+43.85)$ & - \\
\hline $\begin{array}{l}\delta^{3} \text { (the ordinal treatment considers the estimation of three } \\
\text { extra parameters in the measurement model) }\end{array}$ & $+1.52(+46.11)$ & - \\
\hline Alternative specific constant (ASV) & - & - \\
\hline \multicolumn{3}{|l|}{ STATISTICS } \\
\hline \#observations & 1364 & \\
\hline $\begin{array}{l}\text { Init-log-likelihood (only the log-likelihood associated with the discrete choice component is } \\
\text { considered) }\end{array}$ & -944.760 & \\
\hline Final log-likelihood & -779.81 & \\
\hline Rho-square & 0.212 & \\
\hline
\end{tabular}

$t$-Test values are given in parenthesis. $\delta^{j}$ refers to the thresholds estimation for the ordinal logit model.

depending on the trade-off between the vehicle market value and the kit market price, for upgrading the owned vehicle, and also for revaluating the owned old vehicle (in terms of emissions reduction and of fuel consumption). Nevertheless, a user owning a diesel vehicle is less interested in the kit due to the smaller benefits in terms of travel costs. These results confirm that the monetary gain achievable installing the kit is the main boost.

Furthermore, the usual trip purpose also affects the installation choice. Indeed, travelling by car for shopping and personal services, positively increases the utility to install the kit, whilst travelling by car for work purposes has an opposite effect. In this case, travel distances are greater and the users' distrust in the technology may play a significant role.

Finally, the $\Delta_{\text {cost }}$ which has been defined as the difference between the weekly costs with the kit and weekly cost without the kit [16], as expected, was statically significant, increasing the probability of installation choice decreases.

Among all the above-mentioned attributes, the most innovative ones were those aimed at capturing the respondents' nonobservable determinants (attitudinal attributes). In particular, the three following LVs were statistically significant (see Table 7 and refer to the path diagram in Figure 2):

(i) $\mathrm{LV}_{\text {Consumption }}$ representing the attitude towards fuel consumption

(ii) $L V_{\text {Design }}$ representing the attitude towards the vehicle design

(iii) $\mathrm{LV}_{\text {Environment }}$ representing the attitude towards the environment
The reported results refer to the HCM statistically significant model out of three different models that were calibrated using different sets of questions (already introduced in Section 4.2):

(1) With only direct questions (related to the choice context-Q);

(2) With only indirect questions (independent from the choice context-I);

(3) Mixing direct and indirect questions $(Q+I)$.

Estimation results pointed out that no statistically significant measurement equations (thus no HCM) were obtained using only direct or only indirect questions, whilst the mix of both types of questions made it possible to obtain a consistent and robust model (see also Table 8).

Indeed, the results highlight that attitudes may be fruitfully "grasped" by a proper mix of direct and indirect questions. In this sense, if on one hand the attitudes may be considered endogenous to the users and not dependent on the choice context in which the users are called to make a decision, on the other hand the attitudes cannot be considered totally independent from the alternatives under investigation; thus, they should be "grasped" by direct questions.

All the LVs contributed significantly to the systematic utilities, but they showed different magnitudes. Indeed, the latent variable representing the attitude towards the fuel consumption had a relative weight greater than the other two LVs; the latent variable representing the attitude towards the environment showed a weight greater than the LV representing the attitude towards the design. These results confirm the preliminary analyses of the psychometric indicators discussed in Section 4.2. 


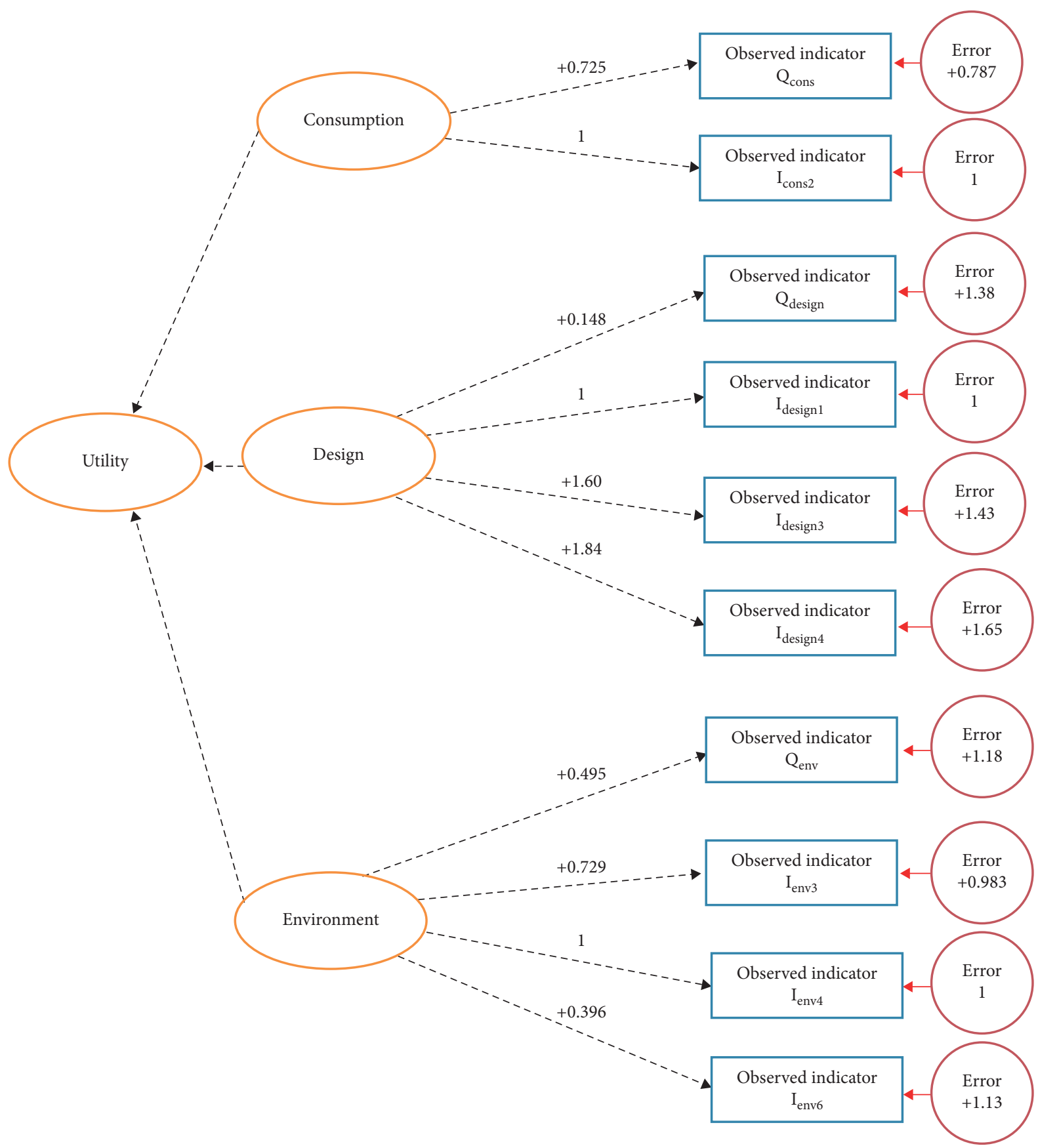

Figure 2: Path diagram of the measurement equations.

Analysing the LVs specification, the indicators (statements) which were statistically significant for each LV have been grouped in Table 8 .

It is thus possible to understand which statement was significant in interpreting the observed choice behaviour. In particular, two indicators were significant in $L_{\text {consumption, }}$ whilst three indicators were significant in $L V_{\text {design }}$ and $\mathrm{LV}_{\text {environment }}$ (for each one of two latent variables one more indicator was considered and normalised thus in all four indicators are considered for each attitude).

Table 9 reports the relationships between the perception indicators and the attitudes and, in particular, shows the estimation results for the following parameters: the coefficient of the latent variables $(\lambda)$, the intercept $(\alpha)$, and error terms $(v)$.

Although the interpretation of the parameters is not immediate, the results indicate the robustness of the estimates and of the whole procedure; moreover, they highlight that the signs are coherent with the preliminary statistical analyses carried out in Section 4 and the coefficient $\lambda$ plays a significant role with respect to the intercept $(\alpha)$ and error terms $(v)$.

Finally, the estimation results for the HCM structural model are displayed in Table 10. 
TABle 8: Attitudes and indicators.

\begin{tabular}{|c|c|c|}
\hline \multicolumn{3}{|c|}{ Measurement model } \\
\hline Consumption & Design & Environment \\
\hline $\begin{array}{l}\text { Q cons } \\
\text { One of the most important things } \\
\text { in a car is the fuel consumption rate }\end{array}$ & $\begin{array}{l}\text { Q } \\
\text { Thesign } \\
\text { The car design is one of the most } \\
\text { important factors in purchasing a car }\end{array}$ & $\begin{array}{c}\mathbf{Q}_{\mathrm{env}} \\
\begin{array}{c}\text { I normally behave or act to reduce the environmental } \\
\text { impact of my actions }\end{array}\end{array}$ \\
\hline $\begin{array}{l}\text { I } \begin{array}{l}\text { cons2 } \\
\text { I am usually attentive to the special } \\
\text { offers of electric operators }\end{array}\end{array}$ & $\begin{array}{c}\mathbf{I}_{\mathbf{d e s i g n 1}} \\
\text { When parking I am usually careful to } \\
\text { avoid having my car damaged }\end{array}$ & $\begin{array}{c}\mathbf{I}_{\text {env3 }} \\
\text { I really enjoy spent my free time in parks, green areas to } \\
\text { breathe clean area }\end{array}$ \\
\hline & $\begin{array}{l}\mathbf{I}_{\mathbf{d e s i g n} 3} \\
\text { When furnishing I am willing to buy } \\
\text { pieces with modern design features and } \\
\text { original details }\end{array}$ & $\begin{array}{l}\mathbf{I}_{\text {env4 }} \\
\text { How much do you agree with the following sentence: we } \\
\text { must act and make decisions to reduce emissions of } \\
\text { greenhouse gases }\end{array}$ \\
\hline & $\begin{array}{l}\text { I } \mathbf{I}_{\text {design4 }} \\
\text { I am willing to go to the body shop } \\
\text { mechanic not only for major damages }\end{array}$ & $\begin{array}{l}\mathbf{I}_{\text {env6 }} \\
\text { I am not willing to use the car during weekend to protect } \\
\text { the environment and then reduce air pollution }\end{array}$ \\
\hline
\end{tabular}

TABLE 9: Estimation results for the measurement models of HCM.

\begin{tabular}{|c|c|c|c|c|c|}
\hline \multicolumn{6}{|c|}{ Measurement model } \\
\hline $\mathrm{LV}_{\mathrm{cc}}$ & & \multicolumn{2}{|c|}{$\mathrm{LV}_{\text {Design }}$} & \multicolumn{2}{|c|}{$\mathrm{LV}_{\text {environment }}$} \\
\hline$Q_{\text {con }}$ & & \multicolumn{2}{|c|}{$Q_{\text {design }}$} & \multicolumn{2}{|c|}{$Q_{\text {env }}$} \\
\hline$\alpha_{10}$ & $+0.567(+3.46)$ & $\alpha_{20}$ & $-1.79(-2.77)$ & $\alpha_{30}$ & $-1.89(-24.48)$ \\
\hline$\lambda_{10}$ & $+0.725(+11.40)$ & $\lambda_{20}$ & $+0.148(+0.85)$ & $\lambda_{30}$ & $+0.495(+14.12)$ \\
\hline$v_{10}$ & $+0.787(+16.37)$ & $v_{20}$ & $+1.38(+33.16)$ & $v_{30}$ & $+1.18(+31.06)$ \\
\hline \multicolumn{2}{|c|}{$I_{\text {cons2 }}$} & \multicolumn{2}{|c|}{$\mathbf{I}_{\text {design1 }}$} & \multicolumn{2}{|c|}{$I_{\text {env3 }}$} \\
\hline$\alpha_{12}$ & 0 & $\alpha_{21}$ & 0 & $\alpha_{33}$ & $-1.36(-19.03)$ \\
\hline$\lambda_{12}$ & 1 & $\lambda_{21}$ & 1 & $\lambda_{33}$ & $+0.729(+20.82)$ \\
\hline \multirow[t]{9}{*}{$v_{12}$} & 1 & $v_{21}$ & 1 & $v_{33}$ & $+0.983(+25.99)$ \\
\hline & & \multicolumn{2}{|c|}{$I_{\text {design3 }}$} & \multicolumn{2}{|c|}{$I_{\text {env4 }}$} \\
\hline & & $\alpha_{23}$ & $+2.79(+2.72)$ & $\alpha_{34}$ & 0 \\
\hline & & $\lambda_{23}$ & $+1.60(+5.72)$ & $\lambda_{34}$ & 1 \\
\hline & & $v_{23}$ & $+1.43(+31.24)$ & $v_{34}$ & 1 \\
\hline & & \multicolumn{2}{|c|}{$I_{\text {design4 }}$} & \multicolumn{2}{|c|}{$I_{\text {env6 }}$} \\
\hline & & $\alpha_{24}$ & $+2.79(+2.69)$ & $\alpha_{36}$ & $-1.95(-26.15)$ \\
\hline & & $\lambda_{24}$ & $+1.84(+6.52)$ & $\lambda_{36}$ & $+0.396(+12.18)$ \\
\hline & & $v_{24}$ & $+1.65(+28.17)$ & $v_{36}$ & $+1.13(+31.80)$ \\
\hline
\end{tabular}

The t-test values are given in parenthesis. The indicators for each latent variable are highlighted in bold.

Overall, the trip frequency for specific travel purposes and the following socioeconomic attributes were statistically significant: gender, age, and education level.

Regarding the first latent variable, the $\mathrm{LV}_{\text {Consumption, the }}$ activity-related attributes and the level of attainment (master degree) are statistically significant and contribute to the LV.

In terms of activity-related attributes, travelling by car for shopping purposes or for personal services exhibit different signs; in particular, negative signs in the case of shopping, but positive in the case of personal services. As the trip purpose changes, the users perceive the new technology differently with respect to the fuel consumption.

Regarding the level of attainment, having a master's degree positively affects the $\mathrm{LV}_{\text {Consumption, indicating that a }}$ higher cultural level affects such an attitude.
The age is significant in both structural equations of $L V_{\text {Design }}$ and $L V_{\text {Environment }}$, indeed older people may be more sensitive to vehicle design due to a higher willingness to pay; on the other hand, the environment is perceived more intensely by older people; furthermore, the gender is significant and negative $L V_{\text {Design }}$ and $L V_{\text {Environment, }}$ explaining that females are more sensitive to the design and the environment problems.

In general, it can be observed that the intercepts and the error terms are significant in all LVs.

5.2. Goodness-of-Fit and Sensitivity Analyses. Goodness-of-fit and sensitivity analyses were carried out by comparing the HCM model with a Binomial Logit Model (BNL) displayed 
TABLE 10: Estimation results for structural models of HCM.

\begin{tabular}{lc}
\hline \multicolumn{1}{c}{ Structural model } \\
Attributes & Value \\
\hline $\begin{array}{l}\text { Attitude towards fuel consumption } \\
\left(\mathrm{LV}_{\text {Consumption }}\right)\end{array}$ \\
$\beta_{\text {MEAN1 }}$ & $-2.32(-29.80)$ \\
$\omega_{1}$ & $+0.787(+16.37)$ \\
By car-shopping & $-0.448(-2.52)$ \\
By car-personal services & $+0.550(+3.88)$ \\
Master's degree & $+0.128(+2.22)$ \\
\hline Attitude towards vehicle design $\left(\mathrm{LV}_{\text {Design }}\right)$ & \\
$\beta_{\text {MEAN2 }}$ & $-3.39(-42.17)$ \\
$\omega_{2}$ & $+0.299(+6.96)$ \\
Age & $-0.0955(-2.37)$ \\
Gender & $-0.278(-6.65)$ \\
\hline Attitude towards environment $\left(\mathrm{LV}_{\text {Environment }}\right)$ & - \\
$\beta_{\text {MEAN3 }}$ & $+1.34(+27.18)$ \\
$\omega_{3}$ & $-1.06(-15.60)$ \\
Age & $-1.12(-16.74)$ \\
Gender &
\end{tabular}

in Table 11. The comparison was carried out to investigate the following:

(i) If the same socioeconomic and instrumental attributes are statistically significant with or without the explicit simulation of psychoattitudinal factors through LVs

(ii) If the socioeconomic attributes continue having the same interpretation and the same role

(iii) If the resulting HCM model has the same predictive capability of a traditional approach and/or shows similar sensitivity to the instrumental attributes

Overall, both models presented similar specification of the utility functions, except for the LVs. These results highlight the robustness of hybrid choice modelling based on LVs, and confirm how LVs do not substitute significant attributes in traditional models, but make it possible to better interpret the choice phenomenon, enriching the utility functions.

Moreover, it must be observed that in the HCM the alternative specific constant was not significant in the choice model supporting two further considerations. In fact, HCM embeds the alternative specific constants (intercepts) in the structural and in the measurement equations, thus allowing a different, but clearer, interpretation of the alternative specific constants' role in the systematic utilities.

If both models share similar attributes, it is interesting to investigate if the HCM shows better goodness-of-fit and/or has a different sensitivity to the main instrumental attribute represented by the $\Delta_{\text {cost }}$.

To this aim, together with traditional indicators, specific comparison indicators proposed by de Luca and Cantarella [115] were estimated, whereas direct elasticities were calculated with respect to the $\Delta_{\text {cost }}$ attribute.

To compare the two models, the following indicators were used: (i) The traditional rho-square indicator;

(ii) \%correct, that is the percentage of users in the calibration sample whose observed choices are given the maximum probability (whatever the value) by the model

(iii) $\mathrm{FF}=\sum_{i} p_{i}^{\mathrm{sim}} / N_{\mathrm{users}} \in[0,1]$, Fitting Factor (FF); that is, the ratio between the sum over the users in the sample of the simulated choice probability for the chosen alternative, $p_{\text {user }}^{\text {sim }} \in[0,1]$, and the number of users in the sample, $N_{\text {users }}$;

(iv) \%Clearly Correct, which is the Percent-Correct percentage of users in the sample whose observed choices are given a probability greater than threshold $t$ (considered thresholds are $\geq 60 / 70 / 80 /$ $90 \%$ ) by the model; this indicator makes it possible to obtain a better interpretation than the traditional $\%$ correct.

With respect to the rho-square indicator (see Table 6), the HCM clearly outperforms the BNL model. Whilst, if \% correct indicators show similar values, FF indicators highlight that the HCM model is able to provide a better simulation of the choices made by users (with reference to each respondent); this result is also confirmed by \%Clearly Correct $_{\mathrm{t}}$. Indeed, with respect to different thresholds $t$ greater than 0.5, HCM clearly outperforms the BNL (see Table 12).

The models were also compared in terms of elasticity with respect to the $\Delta$ cost.

In Figure 3, the results of the sensitivity analysis of $\Delta$ Probability of choice to install against $\Delta$ cost increasing (from $10 \%$ to $50 \%$, with intermediate increasing values at $20 \%, 30 \%$ and $40 \%$ ) are shown, respectively, for BNL and HCM. First of all, it should be observed that both models are similarly sensitive to cost; indeed, by increasing the $\Delta$ cost (which means increasing the kit installation cost), the probability to install the kit is negatively affected and the $\Delta$ Probability to install the kit shifts from $-1 \%$ to $-14 \%$ for $\mathrm{HCM}$ and from $-1 \%$ to $-13 \%$ for BNL.

However, if the two models show similar sensitivity to the monetary cost, it is interesting to investigate the sensitivity of the probability to install the kit with respect to the explaining attitudes.

This nonconventional elasticity analysis was carried out to understand if and how a change in the attitudes may affect the choice probabilities.

If it may be argued the meaning of varying an attitude and/or the actual possibility to modify an attitude, on the other hand, the aim of such an analysis is twofold: first the comprehension of the weight of the attitudes within the model specification, thus the need for explicitly simulating them; secondly, which effects may be obtained by acting on the attitudes. Indeed, the attitudes may be affected by exogenous factors, such as different marketing strategies and the fictitious creation of mediatic phenomena.

With regard to our analyses, the values of the LV (attitudes) in the systematic utility functions were increased from $10 \%$ until $100 \%$. In accordance with previous 
TABLE 11: Comparison between BNL model and HCM (only significant attributes are listed).

\begin{tabular}{|c|c|c|}
\hline Attribute & $\mathrm{BNL}$ & $\mathrm{HCM}$ \\
\hline Age & $+0.352(+2.86)$ & $+0.160(+1.87)$ \\
\hline Master's degree & $+0.360(+2.86)$ & $+0.156(+2.16)$ \\
\hline ZonRes & $+0.157(+2.04)$ & $+0.0761(+1.98)$ \\
\hline Diesel & $+0.356(+2.72)$ & $+0.479(+3.52)$ \\
\hline CarAge & $+0.0358(+2.11)$ & $+0.0272(+1.55)$ \\
\hline By car-shopping & $+0.867(+2.34)$ & $+0.669(+1.490)$ \\
\hline By car-personal services & $+0.678(+1.80)$ & $+0.192(+2.53)$ \\
\hline$\Delta_{\text {cost }}$ & $+0.0641(+8.55)$ & $+0.0638(+8.16)$ \\
\hline $\mathrm{LV}_{\text {Consumption }}$ & - & $+0.548(+2.55)$ \\
\hline $\mathrm{LV}_{\text {Design }}$ & - & $+0.0682(+2.46)$ \\
\hline $\mathrm{LV}_{\text {Environment }}$ & - & $+0.104(+1.98)$ \\
\hline ASC & $+1.53(+7.67)$ & - \\
\hline \multicolumn{3}{|l|}{ STATISTICS } \\
\hline \#observations & 1364 & 1364 \\
\hline $\begin{array}{l}\text { Init-log-likelihood (only the log-likelihood associated with the discrete choice component is } \\
\text { considered) }\end{array}$ & -944.760 & -944.760 \\
\hline Final log-likelihood & -780.962 & -779.81 \\
\hline Rho-square & 0.184 & 0.212 \\
\hline
\end{tabular}

$t$-Test values are given in parenthesis. $\delta^{j}$ refers to the thresholds estimation for the ordinal logit model.

TABLE 12: Comparison between BNL and HCM in terms of goodness-of-fit indicators (see [115]).

\begin{tabular}{lcc}
\hline GOF indicators & BNL & HCM \\
\hline \%correct & 70.31 & 70.16 \\
FF & $59.64 \%$ & $65.47 \%$ \\
ClearlyCorrect0.6 & $14.52 \%$ & $21.70 \%$ \\
ClearlyCorrect 0.7 & $11.44 \%$ & $20.82 \%$ \\
ClearlyCorrect 0.8 & $4.25 \%$ & $17.08 \%$ \\
ClearlyCorrect0.9 & $0.22 \%$ & $5.57 \%$ \\
\hline
\end{tabular}

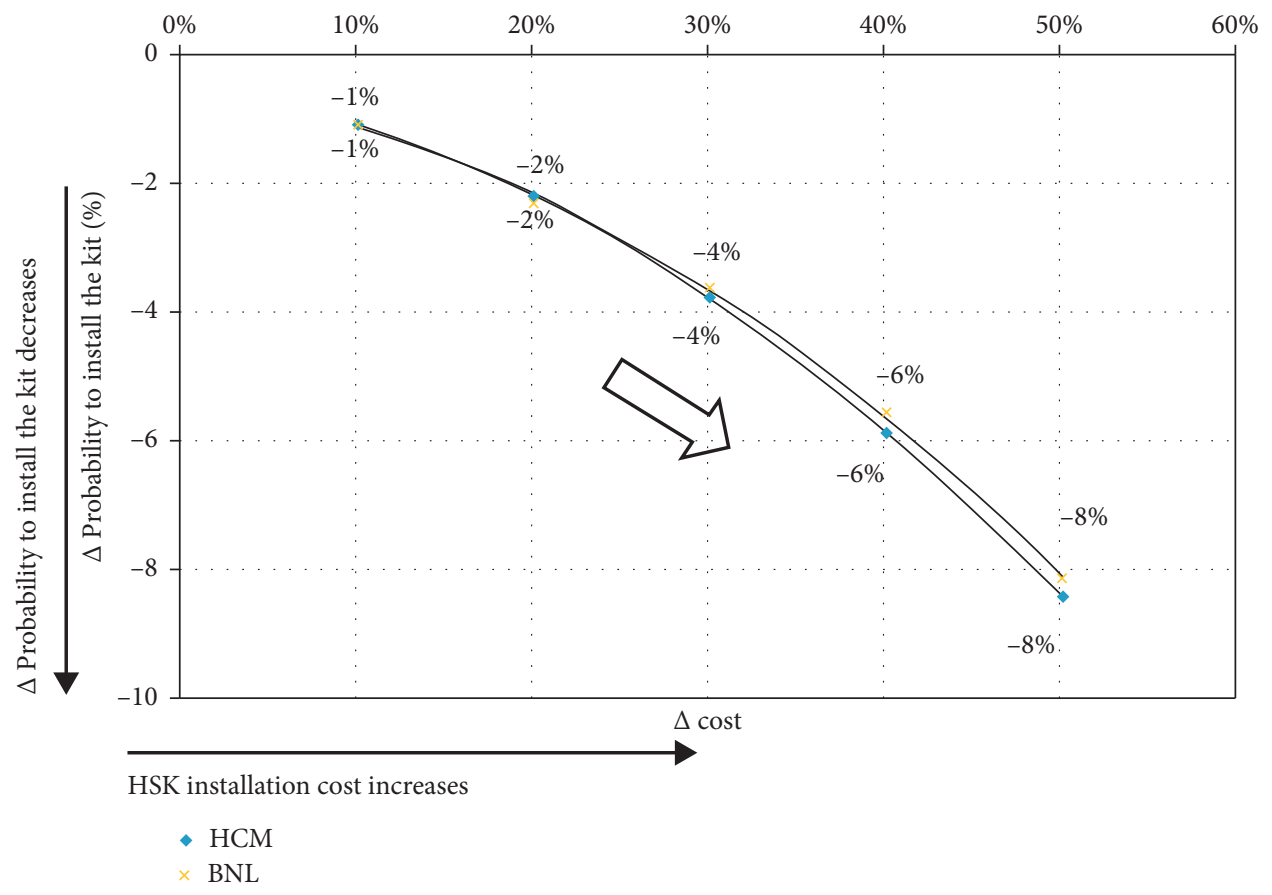

Figure 3: BNL/HCM: sensitivity analysis of $\Delta$ Probability of choice to install against $\Delta_{\text {cost }}$. 


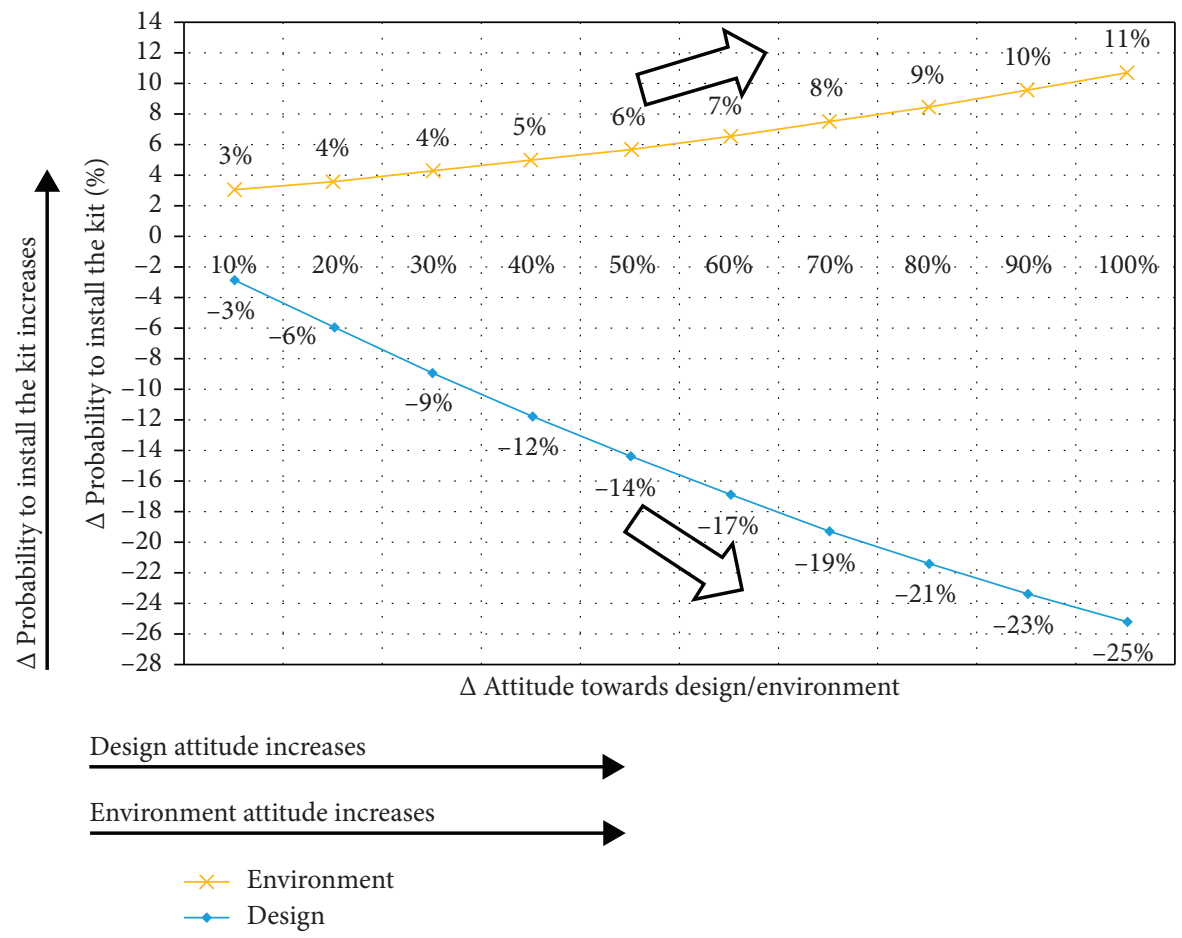

FIGURE 4: HCM: sensitivity analysis of $\triangle$ Probability of choice to install against attitude towards design/environment.

considerations sensitivity analyses were referred to the attitudes towards design and environment. The results are proposed in Figure 4.

First of all, results emphasise that the choice behaviour is significantly affected by the attitudes towards the design and the environment.

In fact, as the $L_{\text {design }}$ increases, the $\Delta$ Probability to install the kit decreases from $-3 \%$ to $-26 \%$; this result indicates that car-makers or decision makers could affect the choice to install the new technology by acting on the attitudes towards design, but also working on the design of the technology itself. In our specific case study, the after-market significantly changes the overall aesthetic of the owned car. With respect to the $L V_{\text {environment }}$, the $\Delta$ Probability variation to install the kit increases from $3 \%$ to $11 \%$. As commented before, acting on the users' proenvironment consciousness and awareness may have significant impact on the choice to install the kit. Also in this case, it could be more effective acting on the attitudes than on the instrumental features of the automotive technology.

\section{Conclusions}

The market penetration and/or the diffusion of innovative technologies call for a realistic interpretation of the user's choice process and require choice models which are effective but can be easily implemented in any operational scenario [116].

A choice process can usually be outlined in different stages (knowledge, persuasion, decision, implementation, and confirmation), and existing literature has widely investigated these phenomena through aggregate approaches founded on the diffusion models/theory [117], or following (user oriented) disaggregate approaches which are able to interpret/model some of the abovementioned stages of the choice process.

Within this framework, the paper aims to investigate the choice behaviour which underpins the decision/implementation stages when using the HySolarkit technology solely as a case study.

In particular, the paper aims to respond to three main research questions:

(i) If and which attitudinal factors significantly affect users' choice of new automotive technology (e.g., after-market hybridization kit), thus if users' choice should be investigated through more advanced and behaviourally complex models

(ii) Which is the most effective surveying approach to observe users' attitudes. Indeed, one of the main issues of choice modelling consists in how to "grasp" users' attitudes and, in particular, through the use of which type of questions (e.g., direct or indirect) as well as through which specific questions.

(iii) How the propensity of choosing a new automotive technology is sensitive to users' attitudes/concerns and changes.

As secondary results, the paper also made it possible to carry out a comparison between a Hybrid choice model (HCM) with Latent Variables (LVs) and a traditional binomial Logit model (BNL), and identified which kind of attitude plays a role in the propensity to install a new and "greener" automotive technology. 
The above research questions were addressed by carrying out a stated preferences survey which investigated the choice of installing an after-market hybridization kit and collected attitudinal factors through direct and indirect questions.

Estimation results highlighted that attitudinal factors significantly affect users' choice. Indeed, three (of the five investigated attitudes) were statistically significant and highlighted that the HCM with LVs model was able to effectively interpret the users' choice. The statistically significant attitudes were:

(i) Attitude towards the "environment"

(ii) Attitude towards the "fuel consumption"

(iii) Attitude towards the "vehicle design"

If the first two attitudes are in line with the study expectations, the attitude towards the design reveals the role of aesthetic factors. By contrast, the attitudes regarding the technology and the reliability of technology did not turn out to be statistically significant, highlighting that the users' behaviour is not influenced by being a "technologically oriented/captive" user.

In terms of magnitude, the latent variable representing the attitude towards "fuel consumption" showed a relative weight greater than the other two LVs, whereas the latent variable representing the attitude towards the "environment" showed a weight greater than the LV representing the attitude towards the "design".

The analysis of the Logit model formulation was carried out to compare the systematic utility specifications and, secondarily, to compare the models in terms of the goodness-of-fit.

The primary consideration is that the two models share almost the same specification of the utility functions, except for the LVs. These results highlight how attributes that are significant in traditional models continue to be significant in the HCM and how the LVs do not substitute these attributes, but enrich the utility functions allowing for a better interpretation of the choice phenomenon.

Furthermore, the socioeconomic attributes which are statistically significant in the BNL become statistically significant in the specification of the LVs only. Such a result confirms that the HCM specification also makes it possible to better classify the socioeconomic attributes, highlighting their role in the interpretation of the users' attitudes within the LVs.

Regarding the goodness-of-fit, it has been shown that the HCM outperforms the BNL, also allowing for a better market share prediction.

With regards to the approach that aims to "grasp" the attitudes, no statistically significant results were obtained using only direct or only indirect questions, whilst the mix of both types of questions made it possible to obtain a consistent and robust model. Therefore, the first attitudes may be considered endogenous to the users; thus, they should be "grasped" by indirect questions regarding the respondent's generic preferences; secondly, the attitudes cannot be considered as being totally independent from the choice context under investigation; thus, they should be "grasped" by direct questions regarding the respondent's preferences specifically related to the choice context.

Finally, although both models showed a similar sensitivity to the instrumental attributes (installation cost), the sensitivity analysis on the HCM model showed how the choice probabilities are extremely sensitive to the attitude variation. In particular, the choice behaviour is more sensitive to the attitudes towards the "design" and the "environment".

Such results indicate that decision makers and/or industries may pursue sustainability goals acting not only on the instrumental features of a technology, but also trying to induce a behavioural change through the modification of the user's attitudes, concerns, and/or perceptions. They could work on specific strategies, such as the promotion of educational programmes, the development of "ad hoc" marketing strategies, and/or the creation of social phenomena through the current social platforms.

In conclusion, the adoption of new technologies requires effective modelling solutions which are able to simulate the choice process and/or allow for a wide interpretation of the phenomenon. From a political point of view, the market penetration of sustainable technologies depends on the instrumental features of the technology, but it can be significantly affected by acting on and/or cultivating "users' background, feelings, and emotions".

Indeed, this field is complex and worthy of further research and it is the authors' opinion that future perspectives should focus on three main streams.

Firstly, a significant amount of effort should be placed on the development/implementation of alternative theoretical paradigms which are able to embed the psychological factors within behavioural paradigms unlike the utilitarian framework. Moreover, such paradigms should be integrated in a unique behavioural framework, coherent with the five stages of the diffusion paradigms: knowledge, persuasion, decision, implementation, and confirmation. The integration of behavioural choice models within the "diffusion paradigm" might give interesting insights for a better understanding of the diffusion process and would be of support in interpreting and modelling the "knowledge" and "persuasion" stages which are rather overlooked in the literature.

Secondly, it could also be relevant to investigate if and how the diffusion of a new technology could be affected by its environmental impact. Indeed, even though a technology might be attractive, this could determine negative feelings from the potential users. This aspect, which does not hold for the HySolarKit, should be explicitly observed and modelled.

Finally, another crucial research field concerns the investigation of different and reliable, but easy to deploy, approaches for capturing and measuring the user's psychological factors which in turn affect users' behaviour. Indeed, the use of the Likert scale and/or the use of absolute judgments may not effectively represent the user's perceptions. 

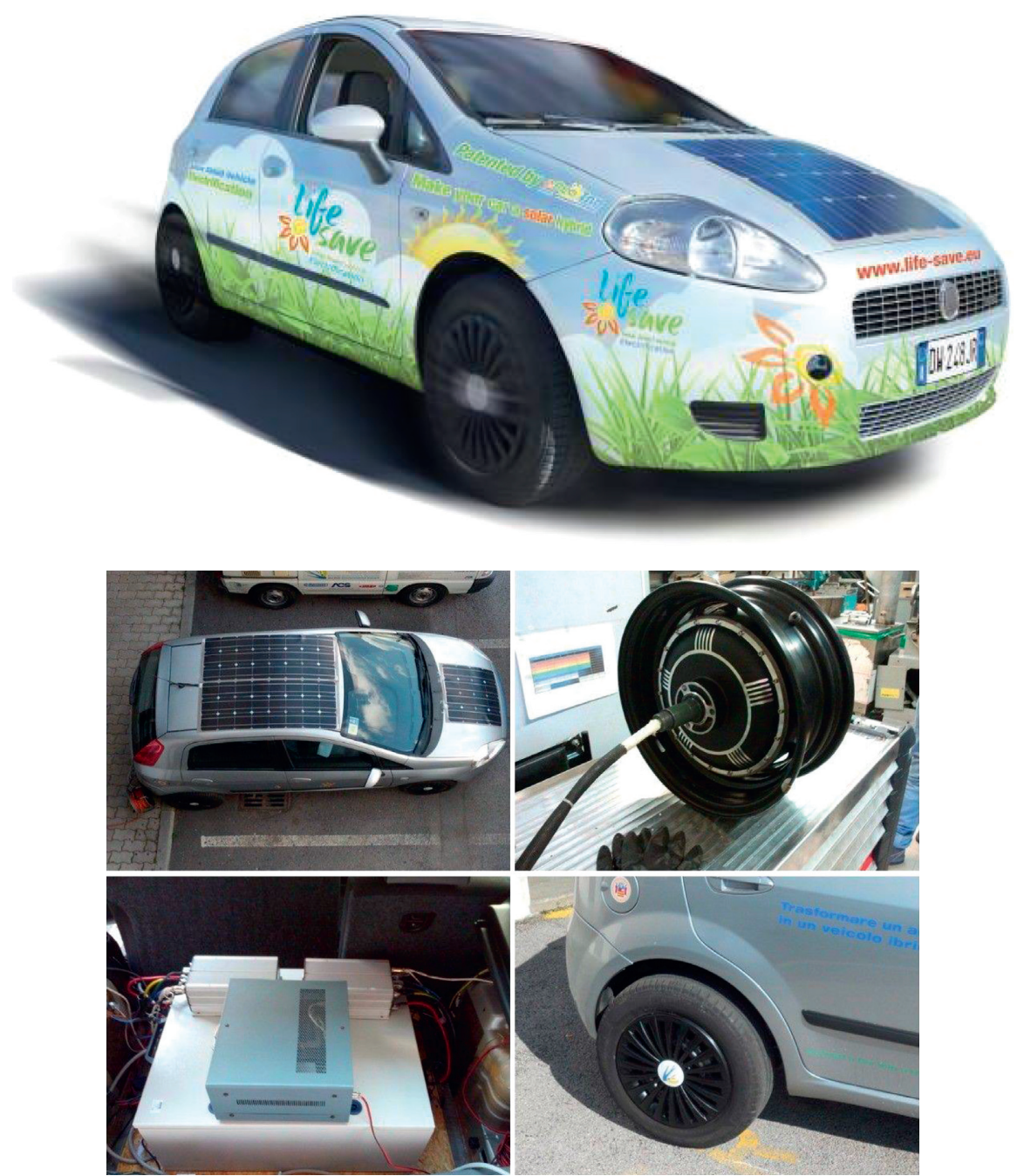

FIgUre 5: HySolar kit (HSK)-vehicle integration.

\section{Appendix}

\section{Technological Framework}

In this paper, the HySolarKit (HSK, see Figure 5) developed by the E-Prob Lab of the University of Salerno (Italy) has been considered. The technology is an aftermarket mild hybridization kit based on the idea that conventional vehicles may be upgraded to hybrid vehicles by means of the electrification of the rear wheels in front-wheel-drive vehicles, adopting in-wheel motors plug-in HEVs $[17,18,20,21]$. Concerning the battery, it may be recharged in three alternative ways: by the rear wheels when operating in generation mode, by photovoltaic panels, or by a regular electric power outlet when the vehicle is connected to the power grid in plug-in mode [19]. In terms of reliability, it is estimated that the battery duration in fully charged conditions is around $15 \mathrm{Km}$ in hybrid mode and in an urban context.

A more detailed description of the vehicle management unit and on-board diagnostics protocol gate is provided in [22].

\section{Data Availability}

The data are available under request to the University of Salerno.

\section{Conflicts of Interest}

The authors declare that there are no conflicts of interest regarding the publication of this paper.

\section{Acknowledgments}

This research was partially supported by the University of Salerno, Italy, EU under local grant no. ORSA171328, financial year 2017. The authors wish also to thank prof. Gianfranco Rizzo and the LIFE-SAVE project (Solar Aided Vehicle Electrification, LIFE16 ENV/IT/000442) that inspired the line of research.

\section{References}

[1] F. J. Bahamonde-Birke, U. Kunert, H. Link, and J. d. D. Ortúzar, "About attitudes and perceptions: finding 
the proper way to consider latent variables in discrete choice models," Transportation, vol. 44, no. 3, pp. 475-493, 2017.

[2] R. A. Daziano and D. Bolduc, "Incorporating pro-environmental preferences towards green automobile technologies through a Bayesian hybrid choice model," Transportmetrica A: Transport Science, vol. 9, no. 1, pp. 74106, 2013.

[3] M. Vredin Johansson, T. Heldt, and P. Johansson, "The effects of attitudes and personality traits on mode choice," Transportation Research Part A: Policy and Practice, vol. 40, no. 6, pp. 507-525, 2006.

[4] C. Domarchi, A. Tudela, and A. González, "Effect of attitudes, habit and affective appraisal on mode choice: an application to university workers," Transportation, vol. 35, no. 5 , pp. 585-599, 2008.

[5] K. M. N. Habib, L. Kattan, and M. T. Islam, "Why do the people use transit? A model for explanation of personal attitude towards transit service quality," in Proceedings of the 88th Annual Meeting of the Transportation Research Board, Washington, DC, USA, January 2009.

[6] B. Atasoy, A. Glerum, R. Hurtubia, and M. Bierlaire, "Demand for public transport services: integrating qualitative and quantitative methods," in Proceedings of the 10th Swiss Transport Research Conference, Ascona, Switzerland, September 2010.

[7] M. F. Yáñez, S. Raveau, and J. D. D. Ortúzar, "Inclusion of latent variables in mixed logit models: modelling and forecasting," Transportation Research Part A: Policy and Practice, vol. 44, no. 9, pp. 744-753, 2010.

[8] D. Bolduc and R. Alvarez-Daziano, "On estimation of hybrid choice models," in Choice Modelling: The State-Of-The-Art and the State-Of-Practice: Proceedings from the Inaugural International Choice Modelling Conference, pp. 259-287, Emerald Group Publishing Limited, Bingley, UK, 2010.

[9] G. Correia and J. M. Viegas, "Carpooling and carpool clubs: clarifying concepts and assessing value enhancement possibilities through a Stated Preference web survey in Lisbon, Portugal," Transportation Research Part A: Policy and Practice, vol. 45, no. 2, pp. 81-90, 2011.

[10] G. H. de Almeida Correia, J. de Abreu e Silva, and J. M. Viegas, "Using latent attitudinal variables estimated through a structural equations model for understanding carpooling propensity," Transportation Planning and Technology, vol. 36, no. 6, pp. 499-519, 2013.

[11] K. Choocharukul, H. T. Van, and S. Fujii, "Psychological effects of travel behavior on preference of residential location choice," Transportation Research Part A: Policy and Practice, vol. 42, no. 1, pp. 116-124, 2008.

[12] Y. O. Susilo and R. Kitamura, "Structural changes in commuters' daily travel: the case of auto and transit commuters in the Osaka metropolitan area of Japan, 1980-2000," Transportation Research Part A: Policy and Practice, vol. 42, no. 1, pp. 95-115, 2008.

[13] E. Parkany, R. Gallagher, and P. Viveiros, "Are attitudes important in travel choice?" Transportation Research Record: Journal of the Transportation Research Board, vol. 1894, no. 1, pp. 127-139, 2004.

[14] C. G. Prato, S. Bekhor, and C. Pronello, "Latent variables and route choice behavior," Transportation, vol. 39, no. 2, pp. 299-319, 2012.

[15] S. Bekhor and G. Albert, "Accounting for sensation seeking in route choice behavior with travel time information," Transportation Research Part F: Traffic Psychology and Behaviour, vol. 22, pp. 39-49, 2014.
[16] S. de Luca, R. Di Pace, and V. Marano, "Modelling the adoption intention and installation choice of an automotive after-market mild-solar-hybridization kit," Transportation Research Part C: Emerging Technologies, vol. 56, pp. 426-445, 2015.

[17] I. Arsie, G. Rizzo, and M. Sorrentino, "Optimal design and dynamic simulation of a hybrid solar vehicle (no. 2006-012997)," SAE Transactions-Journal of Engines, vol. 115, no. 3, pp. 805-811, 2007.

[18] G. Rizzo, I. Arsie, and M. Sorrentino, "Hybrid solar vehicles," Solar Collectors and Panels, Theory and Applications, InTech, West Palm Beach, FL, USA, 2010.

[19] G. Rizzo, I. Arsie, and M. Sorrentino, "Solar energy for cars: perspectives, opportunities and problems," in Proceedings of the GTAA Meeting, Université de Mulhouse, Mulhouse, France, May 2010.

[20] I. Arsie, M. D’Agostino, M. Naddeo, G. Rizzo, and M. Sorrentino, "Toward the development of a through-theroad solar hybridized vehicle," IFAC Proceedings Volumes, vol. 46 , no. 21 , pp. 806-811, 2013.

[21] G. Rizzo, V. Marano, C. Pisanti et al., "A prototype mildsolar-hybridization kit: design and challenges," Energy Procedia, vol. 45, pp. 1017-1026, 2014.

[22] S. de Luca and R. Di Pace, "Aftermarket vehicle hybridization: potential market penetration and environmental benefits of a hybrid-solar kit," International Journal of Sustainable Transportation, vol. 12, no. 5, pp. 353-366, 2018.

[23] J. Kim, S. Rasouli, and H. Timmermans, "Expanding scope of hybrid choice models allowing for mixture of social influences and latent attitudes: application to intended purchase of electric cars," Transportation Research Part A: Policy and Practice, vol. 69, pp. 71-85, 2014.

[24] J. Kim, S. Rasouli, and H. J. P. Timmermans, "The effects of activity-travel context and individual attitudes on carsharing decisions under travel time uncertainty: a hybrid choice modeling approach," Transportation Research Part D: Transport and Environment, vol. 56, pp. 189-202, 2017.

[25] A. Cartenì, E. Cascetta, and S. de Luca, "A random utility model for park \& carsharing services and the pure preference for electric vehicles," Transport Policy, vol. 48, pp. 49-59, 2016.

[26] I. Ajzen, "The theory of planned behavior," Organizational Behavior and Human Decision Processes, vol. 50, no. 2, pp. 179-211, 1991.

[27] B. Lane and S. Potter, "The adoption of cleaner vehicles in the UK: exploring the consumer attitude-action gap," Journal of Cleaner Production, vol. 15, no. 11-12, pp. 1085-1092, 2007.

[28] I. Moons and P. De Pelsmacker, "Emotions as determinants of electric car usage intention," Journal of Marketing Management, vol. 28, no. 3-4, pp. 195-237, 2012.

[29] P. C. Stern, "New environmental theories: toward a coherent theory of environmentally significant behavior," Journal of Social Issues, vol. 56, no. 3, pp. 407-424, 2000.

[30] G. Schuitema, J. Anable, S. Skippon, and N. Kinnear, "The role of instrumental, hedonic and symbolic attributes in the intention to adopt electric vehicles," Transportation Research Part A: Policy and Practice, vol. 48, pp. 39-49, 2013.

[31] E. H. Noppers, K. Keizer, J. W. Bolderdijk, and L. Steg, “The adoption of sustainable innovations: driven by symbolic and environmental motives," Global Environmental Change, vol. 25, pp. 52-62, 2014.

[32] J. Axsen and K. S. Kurani, "Hybrid, plug-in hybrid, or electric-What do car buyers want?" Energy Policy, vol. 61, pp. 532-543, 2013. 
[33] A. Peters and E. Dütschke, "How do consumers perceive electric vehicles? A comparison of German consumer groups," Journal of Environmental Policy \& Planning, vol. 16, no. 3, pp. 359-377, 2014.

[34] M. Petschnig, S. Heidenreich, and P. Spieth, "Innovative alternatives take action-investigating determinants of alternative fuel vehicle adoption," Transportation Research Part A: Policy and Practice, vol. 61, pp. 68-83, 2014.

[35] S. Skippon and M. Garwood, "Responses to battery electric vehicles: UK consumer attitudes and attributions of symbolic meaning following direct experience to reduce psychological distance," Transportation Research Part D: Transport and Environment, vol. 16, no. 7, pp. 525-531, 2011.

[36] E. Graham-Rowe, B. Gardner, C. Abraham et al., "Mainstream consumers driving plug-in battery-electric and plugin hybrid electric cars: a qualitative analysis of responses and evaluations," Transportation Research Part A: Policy and Practice, vol. 46, no. 1, pp. 140-153, 2012.

[37] B. Gardner and C. Abraham, "What drives car use? A grounded theory analysis of commuters' reasons for driving," Transportation Research Part F: Traffic Psychology and Behaviour, vol. 10, no. 3, pp. 187-200, 2007.

[38] E. Mann and C. Abraham, "The role of affect in UK commuters' travel mode choices: an interpretative phenomenological analysis," British Journal of Psychology, vol. 97, no. 2, pp. 155-176, 2006.

[39] L. Steg, "Car use: lust and must. Instrumental, symbolic and affective motives for car use," Transportation Research Part A: Policy and Practice, vol. 39, no. 2-3, pp. 147-162, 2005.

[40] S. Beggs, S. Cardell, and J. Hausman, "Assessing the potential demand for electric cars," Journal of Econometrics, vol. 17, no. 1, pp. 1-19, 1981.

[41] K. Train, "The potential market for non-gasoline-powered automobiles," Transportation Research Part A: General, vol. 14, no. 5-6, pp. 405-414, 1980.

[42] D. A. Hensher, "Functional measurement, individual preference and discrete-choice modelling: theory and application," Journal of Economic Psychology, vol. 2, no. 4, pp. 323-335, 1982.

[43] K. Train, Qualitative Choice Analysis: Econometrics and an Application to 604 Automobile Demand, MIT Press, Cambridge, MA, USA, 1986.

[44] T. E. Golob and D. A. Hensher, "Driving behaviour of long distance truck drivers: the effects of schedule compliance on drug use and speeding citations," International Journal of Transport Economics/Rivista internazionale di economia dei trasporti, vol. 23, pp. 267-301, 1996.

[45] D. Brownstone, D. S. Bunch, T. F. Golob, and W. Ren, “A transactions choice model for forecasting demand for alternative-fuel vehicles," Research in Transportation Economics, vol. 4, pp. 87-129, 1996.

[46] D. Brownstone, D. S. Bunch, and K. Train, "Joint mixed logit models of stated and revealed preferences for alternative-fuel vehicles," Transportation Research Part B: Methodological, vol. 34, no. 5, pp. 315-338, 2000.

[47] J. K. Dagsvik, T. Wennemo, D. G. Wetterwald, and R. Aaberge, "Potential demand for alternative fuel vehicles," Transportation Research Part B: Methodological, vol. 36, no. 4, pp. 361-384, 2002.

[48] D. Bolduc, N. Boucher, and R. Alvarez-Daziano, "Hybrid choice modeling of new technologies for car choice in Canada," Transportation Research Record: Journal of the Transportation Research Board, vol. 2082, no. 1, pp. 63-71, 2008.
[49] A. Hackbarth and R. Madlener, "Consumer preferences for alternative fuel vehicles: a discrete choice analysis," Transportation Research Part D: Transport and Environment, vol. 25, pp. 5-17, 2013.

[50] A. Glerum, L. Stankovikj, M. Thémans, and M. Bierlaire, "Forecasting the demand for electric vehicles: accounting for attitudes and perceptions," Transportation Science, vol. 48, no. 4, pp. 483-499, 2014.

[51] D. J. Santini and A. D. Vyas, Suggestions for a New Vehicle Choice Model Simulating Advanced Vehicles Introduction Decisions (AVID): Structure and Coefficients, Argonne National Laboratory, Argonne, IL USA, 2005.

[52] D. Potoglou and P. S. Kanaroglou, "Household demand and willingness to pay for clean vehicles," Transportation Research Part D: Transport and Environment, vol. 12, no. 4, pp. 264-274, 2007.

[53] K. Sikes, T. Gross, Z. Lin, J. Sullivan, T. Cleary, and J. Ward, "Plug-in hybrid electric vehicle market introduction study," Final report. ORNL/TM-2009/019, US Department of Energy, Washington, DC, USA, 2010.

[54] J. Struben and J. D. Sterman, "Transition challenges for alternative fuel vehicle and transportation systems," Environment and Planning B: Planning and Design, vol. 35, no. 6, pp. 1070-1097, 2008.

[55] L. Qian and D. Soopramanien, "Heterogeneous consumer preferences for alternative fuel cars in China," Transportation Research Part D: Transport and Environment, vol. 16, no. 8, pp. 607-613, 2011.

[56] J. Ahn, G. Jeong, and Y. Kim, "A forecast of household ownership and use of alternative fuel vehicles: a multiple discrete-continuous choice approach," Energy Economics, vol. 30, no. 5, pp. 2091-2104, 2008.

[57] C. G. Chorus, J. M. Rose, and D. A. Hensher, "Regret minimization or utility maximization: it depends on the attribute," Environment and Planning B: Planning and Design, vol. 40, no. 1, pp. 154-169, 2013.

[58] H. Dittmar, The Social Psychology of Material Possessions: To Have Is to Be, Harvester Wheatsheaf, Hemel Hempstead, UK, 1992.

[59] K. E. Voss, E. R. Spangenberg, and B. Grohmann, "Measuring the hedonic and utilitarian dimensions of consumer attitude," Journal of Marketing Research, vol. 40, no. 3, pp. 310-320, 2003.

[60] G. Roehrich, “Consumer innovativeness," Journal of Business Research, vol. 57, no. 6, pp. 671-677, 2004.

[61] S. Shepherd, P. Bonsall, and G. Harrison, "Factors affecting future demand for electric vehicles: a model based study," Transport Policy, vol. 20, pp. 62-74, 2012.

[62] E. Cascetta and A. Cartenì, "The hedonic value of railways terminals. A quantitative analysis of the impact of stations quality on travellers behaviour," Transportation Research Part A: Policy and Practice, vol. 61, pp. 41-52, 2014.

[63] D. S. Bunch, M. Bradley, T. F. Golob, R. Kitamura, and G. P. Occhiuzzo, "Demand for clean-fuel vehicles in California: a discrete-choice stated preference pilot project," Transportation Research Part A: Policy and Practice, vol. 27, no. 3, pp. 237-253, 1993.

[64] E. Chéron and M. Zins, "Electric vehicle purchasing intentions: the concern over battery charge duration," Transportation Research Part A: Policy and Practice, vol. 31, no. 3, pp. 235-243, 1997.

[65] P. Ong and K. Hasselhoff, "High interest in hybrid cars," SCS Fact Sheet, vol. 1, no. 5, 2005. 
[66] S. Musti and K. M. Kockelman, "Evolution of the household vehicle fleet: anticipating fleet composition, PHEV adoption and GHG emissions in Austin, Texas," Transportation Research Part A: Policy and Practice, vol. 45, no. 8, pp. 707-720, 2011.

[67] L. He, W. Chen, and G. Conzelmann, "Impact of vehicle usage on consumer choice of hybrid electric vehicles," Transportation Research Part D: Transport and Environment, vol. 17, no. 3, pp. 208-214, 2012.

[68] S. de Luca and R. Di Pace, "Modelling the propensity in adhering to a carsharing system: a behavioral approach," Transportation Research Procedia, vol. 3, pp. 866-875, 2014.

[69] P. Plötz, U. Schneider, J. Globisch, and E. Dütschke, "Who will buy electric vehicles? Identifying early adopters in Germany," Transportation Research Part A: Policy and Practice, vol. 67, pp. 96-109, 2014.

[70] J. Axsen and K. S. Kurani, "Anticipating plug-in hybrid vehicle energy impacts in California: constructing consumerinformed recharge profiles," Transportation Research Part D: Transport and Environment, vol. 15, no. 4, pp. 212-219, 2010.

[71] S. Bamberg and G. Möser, "Twenty years after Hines, Hungerford, and Tomera: a new meta-analysis of psychosocial determinants of pro-environmental behaviour," Journal of Environmental Psychology, vol. 27, no. 1, pp. 1425, 2007.

[72] M. C. Onwezen, G. Antonides, and J. Bartels, "The norm activation model: an exploration of the functions of anticipated pride and guilt in pro-environmental behaviour," Journal of Economic Psychology, vol. 39, pp. 141-153, 2013.

[73] L. Steg and C. Vlek, "Encouraging pro-environmental behaviour: an integrative review and research agenda," Journal of Environmental Psychology, vol. 29, no. 3, pp. 309-317, 2009.

[74] E. Shih and H. J. Schau, "To justify or not to justify: the role of anticipated regret on consumers' decisions to upgrade technological innovations," Journal of Retailing, vol. 87, no. 2, pp. 242-251, 2011.

[75] L. Watson and M. T. Spence, "Causes and consequences of emotions on consumer behaviour," European Journal of Marketing, vol. 41, no. 5/6, pp. 487-511, 2007.

[76] S. Choo and P. L. Mokhtarian, "What type of vehicle do people drive? The role of attitude and lifestyle in influencing vehicle type choice," Transportation Research Part A: Policy and Practice, vol. 38, no. 3, pp. 201-222, 2004.

[77] K. Kishi and K. Satoh, "Evaluation of willingness to buy a low-pollution car in Japan," Journal of the Eastern Asia Society for Transportation Studies, vol. 6, pp. 3121-3134, 2005.

[78] R. Alvarez-Daziano and D. Bolduc, "Canadian consumers' perceptual and attitudinal responses toward green automobile technologies: an application of Hybrid Choice Models," European Summer School in Resources Environmental Economics: Economics, Transport and Environment, Venice International University, Venice, Italy, 2009.

[79] A. F. Jensen, Development of a Stated Preference Experiment for Electric Vehicle Demand, Master's Thesis, Technical University of Denmark, Lyngby, Denmark, 2010.

[80] A. F. Jensen, E. Cherchi, and S. L. Mabit, "On the stability of preferences and attitudes before and after experiencing an electric vehicle," Transportation Research Part D: Transport and Environment, vol. 25, pp. 24-32, 2013.

[81] J. J. Soto, V. Cantillo, and J. Arellana, "Hybrid choice modelling of alternative fueled vehicles in colombian cities including second order structural equations," in Proceedings of the Transportation Research Board 93rd Annual Meeting (No. 14-4545), Washington, DC, USA, January 2014.

[82] I. Tsouros and A. Polydoropoulou, "Who will buy alternative fueled or automated vehicles: a modular, behavioral modeling approach," Transportation Research Part A: Policy and Practice, vol. 132, pp. 214-225, 2020.

[83] A. Daly, S. Hess, B. Patruni, D. Potoglou, and C. Rohr, "Using ordered attitudinal indicators in a latent variable choice model: a study of the impact of security on rail travel behaviour," Transportation, vol. 39, no. 2, pp. 267-297, 2012.

[84] T. Ioannis, P. Amalia, and T. Athena, "A hybrid choice model for alternative fuel car purchase," in Proceedings of the International Choice Modelling Conference, Cape Town, South Africa, 2015.

[85] J. D. D. Ortúzar and G. A. Hutt, "La influencia de elementos subjetivos en funciones desagregadas de elección discreta," Ingeniería de Sistemas, vol. 4, no. 2, pp. 37-54, 1984.

[86] D. McFadden, "The choice theory approach to market research,” Marketing Science, vol. 5, no. 4, pp. 275-297, 1986.

[87] K. G. Jöreskog, "Simultaneous factor Analysis in several populations," ETS Research Bulletin Series, vol. 1970, no. 2, pp. i-31, 1970.

[88] M. Ben-Akiva, D. McFadden, T. Gärling et al., "Framework for modeling choice behavior," Marketing Letters, vol. 10, no. 3, pp. 187-203.

[89] J. L. Larichev, "Extended discrete choice models: integrated framework, flexible error structures, and latent variables," pp. 80-116, Massachusetts Institute of Technology, Cambridge, MA, USA, 2001, Doctoral dissertation.

[90] D. McFadden, "Economic choices," American Economic Review, vol. 91, no. 3, pp. 351-378, 2001.

[91] M. Ben-Akiva, J. Walker, A. T. Bernardino, D. A. Gopinath, T. Morikawa, and A. Polydoropoulou, "Integration of choice and latent variable models," Perpetual Motion: Travel Behaviour Research Opportunities and Application Challenges, pp. 431-470, Emerald Group Publishing, Bingley, UK, 2002.

[92] J. Walker and M. Ben-Akiva, "Generalized random utility model," Mathematical Social Sciences, vol. 43, no. 3, pp. 303-343, 2002.

[93] S. Raveau, R. Álvarez-Daziano, M. Yáñez, D. Bolduc, and J. de Dios Ortúzar, "Sequential and simultaneous estimation of hybrid discrete choice models: some new findings," Transportation Research Record: Journal of the Transportation Research Board, vol. 2156, no. 1, pp. 131-139, 2010.

[94] M. Kroesen and C. Chorus, "The role of general and specific attitudes in predicting travel behavior-a fatal dilemma?" Travel Behaviour and Society, vol. 10, pp. 33-41, 2018.

[95] R. Krueger, A. Vij, and T. H. Rashidi, "Normative beliefs and modality styles: a latent class and latent variable model of travel behaviour," Transportation, vol. 45, no. 3, pp. 789-825, 2018.

[96] M. Thorhauge, E. Cherchi, J. L. Walker, and J. Rich, "The role of intention as mediator between latent effects and behavior: application of a hybrid choice model to study departure time choices," Transportation, vol. 46, no. 4, pp. 1421-1445, 2019.

[97] W. Li and M. Kamargianni, "An integrated choice and latent variable model to explore the influence of attitudinal and perceptual factors on shared mobility choices and their value of time estimation," Transportation Science, vol. 54, no. 1, 2019.

[98] F. S. Koppelman and J. R. Hauser, "Destination choice behaviour for non-grocery-shopping trips," Transportation Research Record, vol. 673, pp. 157-165, 1978. 
[99] P. E. Green, "Hybrid models for conjoint analysis: an expository review," Journal of Marketing Research, vol. 21, no. 2, pp. 155-169, 1984.

[100] K. M. Harris and M. P. Keane, "A model of health plan choice: inferring preferences and perceptions from a combination of revealed preference and attitudinal data," Journal of Econometrics, vol. 89, no. 1-2, pp. 131-157, 1998.

[101] J. N. Prashker, "Scaling perceptions of reliability of urban travel modes using indscal and factor analysis methods," Transportation Research Part A: General, vol. 13, no. 3, pp. 203-212, 1979.

[102] K. A. Bollen, Structural Equations with Latent Variables, Wiley, New York, NY, USA, 1989.

[103] R. Likert, "A technique for the measurement of attitudes," Archives of psychology, vol. 22, no. 140, 1932.

[104] K. Ashok, W. R. Dillon, and S. Yuan, "Extending discrete choice models to incorporate attitudinal and other latent variables," Journal of Marketing Research, vol. 39, no. 1, pp. 31-46, 2002.

[105] M. L. Tam, W. H. K. Lam, and H. P. Lo, "Modeling air passenger travel behavior on airport ground access mode choices," Transportmetrica, vol. 4, no. 2, pp. 135-153, 2008.

[106] F. J. Bahamonde-Birke and J. D. D. Ortúzar, "On the variability of hybrid discrete choice models," Transportmetrica A: Transport Science, vol. 10, no. 1, pp. 74-88, 2014.

[107] X. Cao, P. L. Mokhtarian, and S. L. Handy, "The relationship between the built environment and nonwork travel: a case study of Northern California," Transportation Research Part A: Policy and Practice, vol. 43, no. 5, pp. 548-559, 2009.

[108] S. Fujii and T. Gärling, "Application of attitude theory for improved predictive accuracy of stated preference methods in travel demand analysis," Transportation Research Part A: Policy and Practice, vol. 37, no. 4, pp. 389-402, 2003.

[109] A. Vij and J. L. Walker, "How, when and why integrated choice and latent variable models are latently useful," Transportation Research Part B: Methodological, vol. 90, pp. 192-217, 2016.

[110] M. Bierlaire and M. Fetiarison, "Estimation of discrete choice models: extending BIOGEME," in Proceedings of the Swiss Transport Research Conference (STRC), Leiden, Netherlands, September 2009.

[111] D. Bolduc and A. Giroux, The Integrated Choice and Latent Variable (ICLV) Model: Handout to Accompany the Estimation Software, D'epartement d'economique, Universit'e Laval, Quebec, Canada, 2005.

[112] G. W. Allport, Handbook of Social Psychology, AddisonWesley, Boston, MA, USA, 1935.

[113] J. Pickens, “Attitudes and perceptions," Organizational Behavior in Health Care, pp. 43-75, Jones and Bartlett Publishers, Sudbury, MA, USA, 2005.

[114] P. H. Lindsay and D. A. Norman, Human Information Processing: An Introduction to Psychology, Academic Press, Cambridge, MA, USA, 2013.

[115] S. de Luca and G. E. Cantarella, "Validation and comparison of choice models," in Success and Failure of Travel Demand Management Measures, W. Saleh, Ed., Vol. 37-58, Ashgate Publications, Farnham, UK, 2011.

[116] S. de Luca and A. Papola, "Evaluation of travel demand management policies in the urban area of Naples," Advances in Transport, vol. 8, pp. 185-194, 2001.

[117] F. M. Bass, K. Gordon, T. L. Ferguson, and M. L. Githens, "Forecasting diffusion of a new technology prior to product launch," Interfaces, vol. 31, no. 3, pp. S82-S93, 2001.
[118] K. A. Bollen, Structural Equations with Latent Variables, John Wiley \& Sons, Hoboken, NJ, USA, 2014.

[119] G. Correia, J. Abreu e Silva, and J. Viegas, "Using latent attitudinal variables for measuring carpooling propensity," in Proceeding of 12th World Conference on Transport Research, Lisbon, Portugal, July 2010.

[120] T. F. Golob, "Structural equation modeling for travel behavior research," Transportation Research Part B: Methodological, vol. 37, no. 1, pp. 1-25, 2003.

[121] T. F. Golob, D. S. Bunch, and D. Brownstone, "A vehicle use forecasting model based on revealed and stated vehicle type choice and utilisation data," Journal of Transport Economics and Policy, vol. 31, pp. 69-92, 1997.

[122] S. Hess, N. Sanko, J. Dumont, and A. Daly, "A latent variable approach to dealing with missing or inaccurately measured variables: the case of income," in Proceedings of the Third International Choice Modelling Conference, pp. 3-5, Sydney, Australia, July 2013.

[123] T. Ohsaki, T. Kishi, T. Kuboki et al., "Overcharge reaction of lithium-ion batteries," Journal of Power Sources, vol. 146, no. 1-2, pp. 97-100, 2005. 